Research Article

\title{
Energy Dissipation and Local, Story, and Global Ductility Reduction Factors in Steel Frames under Vibrations Produced by Earthquakes
}

\author{
Alfredo Reyes-Salazar ${ }^{D}{ }^{1}{ }^{1}$ Edén Bojórquez ${ }^{D},{ }^{1}$ Juan Bojorquez, ${ }^{1}$ \\ Federico Valenzuela-Beltran $\left(\mathbb{D},{ }^{2}\right.$ and Mario D. Llanes-Tizoc $\mathbb{D}^{1}$ \\ ${ }^{1}$ Facultad de Ingeniería, Universidad Autónoma de Sinaloa, Culiacán, CP 80040 Sinaloa, Mexico \\ ${ }^{2}$ Instituto de Ingeniería, Universidad Nacional Autónoma de México, CP 04510 Ciudad de México, Mexico \\ Correspondence should be addressed to Alfredo Reyes-Salazar; reyes@uas.edu.mx
}

Received 5 June 2018; Accepted 17 September 2018; Published 14 October 2018

Academic Editor: Giorgio Dalpiaz

Copyright ( 2018 Alfredo Reyes-Salazar et al. This is an open access article distributed under the Creative Commons Attribution License, which permits unrestricted use, distribution, and reproduction in any medium, provided the original work is properly cited.

\begin{abstract}
Ductility plays a central role in seismic analysis and design of steel buildings. A numerical investigation regarding the evaluation of energy dissipation, ductility, and ductility reduction factors for local, story, and global structural levels is conducted. Some steel buildings and strong motions, which were part of the SAC Steel Project, are used. Bending local ductility capacity $\left(\mu_{\mathrm{L} \phi}\right)$ of beams can reach values of up to 20 , as shown in experimental investigations. The values are larger for medium than for low-rise buildings, reflecting the effect of the structural complexity on $\mu_{\mathrm{L} \phi}$. Most of the dissipated energy occurs on beams; however, resultant stresses at columns are also significantly reduced by beam yielding. A value of $1 / 3$ is proposed for the ratio of global to local ductility; thus, if local ductility capacity is stated as the basis for the design, global ductility capacity can be calculated by using this ratio. It is implicitly assumed in seismic codes that the magnitude of the global ductility reduction factor is about 4; according to the results found in this paper, it is not justified; a value of 3 is observed to be more reasonable. According to the well-known ratio of the ductility reduction factor to ductility, this ratio should be unity for the models under consideration; the results of this study indicate that, for global response parameters, a value of $3 / 4$ is more appropriate and that, for local response parameters, values larger than 2 can be reached; the implication of this is that using simplified methods like the static equivalent lateral force may result in nonconservative designs from a global structural point of view, but in conservative designs from a local point of view. A value of 8 is proposed for the ratio of the global ductility reduction factor to the global normalized energy.
\end{abstract}

\section{Introduction}

Even though building structures undergo significant nonlinear deformations when subjected to strong earthquakes, simple elastic procedures are still used to determine the seismic demands (International Building Code (IBC) [1], National Building Code of Canada (NBCC) [2], Mexico Federal District Code (MFDC) [3], and Eurocode 8 (EC) [4]). Simplified methods like the Static Equivalent Lateral Force (SELF) are broadly used for regular buildings with relatively short periods (low- and medium-rise). However, while using this procedure in steel buildings, it is not possible to properly capture the effects of nonlinearity introduced by large deformations, by the connections, and by nonlinear geometry. In addition, dissipation of energy due to yielding of the material is considered in a very crude way. According to the method, static analysis of the buildings subjected to equivalent lateral forces, which are related to the properties of the structure and the seismicity of the region, provides the design forces. In the procedure, the ductility parameter $(\mu)$ plays an important role in the determination of the design seismic forces since it is associated with the energy dissipation structural capacity produced by nonlinear behavior, allowing for a reduction 
of the elastic strength demands; the larger the ductility, the smaller the design seismic forces. In fact, the magnitude of the reduction of the elastic design seismic forces directly depend on a parameter that, in general, can be called "the reduction factor," which in turn greatly depends on an associated parameter called the ductility reduction factor $\left(\mathrm{R}_{\mu}\right)[5,6]$. It is particularly important for steel structures since the beneficial effect of ductility and energy dissipation is supposed to come from different sources. However, there is not unanimity on the profession on how to define it; it is argued that this parameter is constantly used in the profession in an indirect way to estimate the building seismic design forces, but there is no engineering definition of it in our specifications $[7,8]$. Defining the magnitude of these parameters represents one of the most controversial issues in the SELF procedure.

The reduction factor receives the name of the response modification factor $(R)$, force modification factor $\left(R_{\mathrm{d}}\right)$, seismic reduction factor $\left(Q^{\prime}\right)$, and seismic reduction factor $\left(q^{\prime}\right)$ in the IBC, NBCC, MFDC, and EC codes, respectively. It is implicitly or explicitly assumed in these codes that ductility represents the capacity of the structure to dissipate energy and that the reduction of the elastic demands importantly depends on the ductility capacity.

Thus, the ductility parameter and the ductility reduction factors play a central role in the seismic design of steel buildings; for that reason, it has been an important research topic during the last recent decades. However, there are many aspects that need additional attention; some of them are addressed in this research. As it is further elaborated below, the central objective of this paper is to evaluate the ductility parameter, the ductility reduction factor $\left(R_{\mu}\right)$, for steel buildings with moment-resisting frames (MRF) for different structural levels (local, story, and global) relating them with the dissipated energy. The evaluation of the $\mu$ and $R_{\mu}$ parameters according to sophisticated nonlinear analysis procedures to capture the effects of the mentioned sources of nonlinearity is needed. It is accepted that nonlinear time history analysis is the most accurate and reliable analysis procedure providing a realistic modeling of the structure as well as of the cyclic load deformation characteristics of its structural elements. Extensive seismic nonlinear timehistory analyses are performed in this investigation to reach the objectives of the study. The results are compared with those specified in the codes.

\section{Literature Review and Objectives}

Investigations regarding nonlinear analysis of buildings under the action of earthquakes, following different objectives, have been conducted by many researchers during the last decades. In this regard, since this dissipation of energy allows for a reduction of the elastic seismic forces, the quantification of the ductility demand, the ductility reduction factor, and the force (or seismic) reduction factor is of particular interest. There have been many studies considering concrete or steel buildings modeled as SDOF or simple systems. Introduced first in ATC [9] at the end of the 70 s, the modification factor was used to reduce the elastic response (base shear) obtained from a 5\% damped acceleration response spectra. Among the first investigations, we can also find those of Newmark and Hall [10], and they proposed a procedure to relate $R_{\mu}$ and $\mu$ based on the basic elastic design spectra. Hadjian [11] calculated the spectral accelerations considering the nonlinear deformation of structures. Miranda and Bertero [12] proposed simplified expressions to estimate the inelastic design spectra as a function of the maximum tolerable ductility. Whitaker et al. [13] proposed calculating $R$ as the product of factors accounting for viscous damping, ductility, and overstrength. Arroyo-Espinoza and Teran-Gilmore [14] from the dynamic response of SDOF systems proposed expressions to calculate $\mathrm{R}_{\mu}$. Levy et al. [15] derived approximate harmonic equivalent stiffness and damping for bilinear systems in the context of earthquake resistant. Karmakar and Gupta [16] by using elastoplastic oscillators performed a parametric study to estimate the dependence of strength reduction factors on strong motion duration, earthquake magnitude, geological site conditions, and epicentral distance. Rupakhety and Sigbjörnsson [17] presented ground-motion prediction equations which describe constant-ductility inelastic spectral ordinates and structural behavior factors to be applied within the framework of Eurocode 8. Sanchez-Ricart [18] reviewed the backgrounds that support the values of the reduction factor in the United States, Europe, and Japan. Halabian and Kabiri [19] evaluated the effect of the foundation flexibility on the ductility reduction factors of reinforced concrete stack-like structures. AlHamaydeh et al. [20] investigated the force reduction factors for reinforce concrete frame buildings designed according to the IBC code. Naimi et al. [21] studied the reduced beam section approach via the introduction of multilongitudinal voids in the beam web for various beam depths, where the ANSYS finite element program was used in the numerical simulation. An improvement in the connection ductility was observed since the input energy was dissipated uniformly along the beam length. Azimi et al. [22] proposed a new beam to column connection and numerically and experimentally showed that the new connection could improve the ultimate structural lateral resistance, ductility, and energy dissipation capacity. Fanaie and Shamlou [23] calculated the overstrength, ductility, and response modification factors for frames braced with a different type of buckling restrained braces. Zhai et al. [24] investigated the strength reduction factor of SDOF systems with constant ductility performance subjected to the mainshock-aftershock sequence-type ground motions. Wang et al. [25] studied the nonlinear behavior of prestressed steel reinforced concrete beams by using finite element analysis. Based on the model, they analyzed the effect of prestressed force to the stiffness, the ultimate bearing capacity, and ductility of the beams. Cho et al. [26] investigated the shear design equations for prestressed hollow-core slabs and examined the magnitude of the strength reduction factors based on the structural reliability theory. The results showed that the shear strengths of the members with the heights of more than $315 \mathrm{~mm}$ are excessively safe, whereas some members with low depths did not satisfy the target reliability index. 
There are also several studies regarding the evaluation $R_{\mu}$ and $\mu$ factors for multidegree of freedom (MDOF) systems. Nassar and Krawinkler [27] studied the relationship between force reduction factors and ductility for SDOF and simplified (three-story single-bay) MDOF systems. Moghaddam and Mohammadi [28] introduced a modification to the response modification factor and proposed an approach to evaluate the seismic strength and ductility demands of MDOF structures. Elnashai and Mwafy [29] investigated the relationship between the lateral capacity, the design force reduction factor, the ductility factor, and the overstrength factor for reinforced-concrete buildings. Reyes-Salazar [8] studied the ductility capacity of plane steel moment-resisting frames. Medina and Krawinkler [30] presented an evaluation on drift demands for regular moment-resisting frame structures subjected to ordinary ground motions considering the uncertainty due to differences in the frequency content of the ground motions. De Stefano et al. [31] studied the effects of the overstrength on the seismic behavior of multistory asymmetric buildings. Cai et al. [32] estimated ductility reduction factors for MDOF systems by modifying ductility reduction factors of SDOF systems through a modification factor. Chopra [33] studied the ductility reduction factors for MDOF systems modeled as shear buildings and their corresponding equivalent SDOF systems. Mollaioli and Bruno [34] developed constant ductility spectra for SDOF and MDOF systems. Vielma et al. [35] studied the seismic damage and safety assessment of buildings with low ductility used in Spain by using pushover and dynamics analysis. Ceylan et al. [36] estimated the strength reduction factor for prefabricated industrial structures having a single story, one, and two bays. Honglue el al. [37] estimated the accuracy of strength reduction factors proposed by other investigators by using a suite of near-fault earthquake records with directivity-induced pulses. Ganjavi and Hao [38] studied the seismic response of linear and nonlinear MDOF systems subjected to a group of earthquakes recorded on alluvium and soft soils. Serror et al. [39] evaluated the values of both damping and ductility reduction factors for steel moment-resisting frames with supplemental linear viscous dampers. Bojorquez et al. [40] assessed the effect of cumulative damage on the strength requirements of degrading structures through the evaluation of the target ductility and corresponding strength reduction factors of simple degrading structures. The results provide insight into all relevant parameters that should be considered during seismic design of earthquake-resistant structures, and some recommendations to evaluate the effect of cumulative damage on seismic design are suggested. Chaulagain et al. [41] by using pushover analysis studied the effects of overstrength on the ductility factor of reinforced concrete buildings. Reyes-Salazar et al. [42] studied the ductility reduction factor for buildings with momentresisting steel frames (MRSF) which were modeled as complex MDOF systems, considering an intermediate level of inelastic structural deformation. Vuran and Aydınoğlu [43] developed simple capacity and ductility demand estimation tools for coupled core wall systems to be implemented during the preliminary design stage of such structural system.
Gómez-Martínez et al. [44] analytically studied the local and global ductility of wide-beam reinforced concrete momentresisting frames. Liu et al. [45], for the SDOF system and considering spatially varying ground motions, developed a new response spectrum method by incorporating the ductility factor and strain rate into the conventional response spectrum method. Hashemi et al. [46] presented the results of studies on two important seismic parameters, namely, ductility and response modification factor for moment-resisting frames with concrete-filled steel tube columns.

The abovementioned studies represent a significant contribution regarding the evaluation of ductility or ductility reduction factors; however, in most of them, SDOF systems or a limited level of inelastic deformation were considered. Therefore, they did not explicitly consider the energy dissipation associated with nonlinear behavior of the structural elements existing in actual systems. It has been shown $[8,47-49]$ that ductility demands and the ductility reduction factors depend on the amount of dissipated energy, which in turn depends on the pattern of plastic hinges formed in the frames as well as on the loading, unloading, and reloading process at plastic hinges. In addition, a limited level of inelastic deformation is not associated with the ductility capacity. Moreover, local, story, and global ductility, as well as local, story and global ductility reduction factors, as well as relationships among them taking into account the dissipated energy, have not been studied.

The objectives of this research are as follows:

(1) Calculate local ductility demands (in terms of curvatures) and capacities for individual structural elements (beams and columns) as well as story and global ductility demands and capacities. The ratio of local to global ductility is also estimated.

(2) Calculate the ductility reduction factors as well as the ratio of the ductility reduction factor to ductility, for the three structural levels under consideration, and compare them with those specified in the codes.

(3) Estimate the energy demands for local, story, and global levels as well as the ratio of the ductility reduction factor to dissipated energy.

\section{Methods, Procedure, and Structural Models}

3.1. Steel Building Models. As part of the SAC Steel Project [50], several steel building models were designed, which are supposed to satisfy the code requirements at the time the project started, for the following cities: Los Angeles (IBC), Seattle (IBC), and Boston (BOCA) [51]. The perimeter moment-resisting frames (PMRF) of the 3- and 10-level buildings used in the project located in the Los Angeles area are considered in this study to address the issues discussed earlier. Isometric views of the buildings are shown in Figures 1 and 2, where the PMRF can be easily identified (exterior frames); they are referred hereafter as Models 1 and 2, respectively. The beams and columns of the models were designed following the strong column-weak beam (SC-WB) concept; sizes of beams and columns for the PMRF, as reported, are given in Table 1. The first three translational 


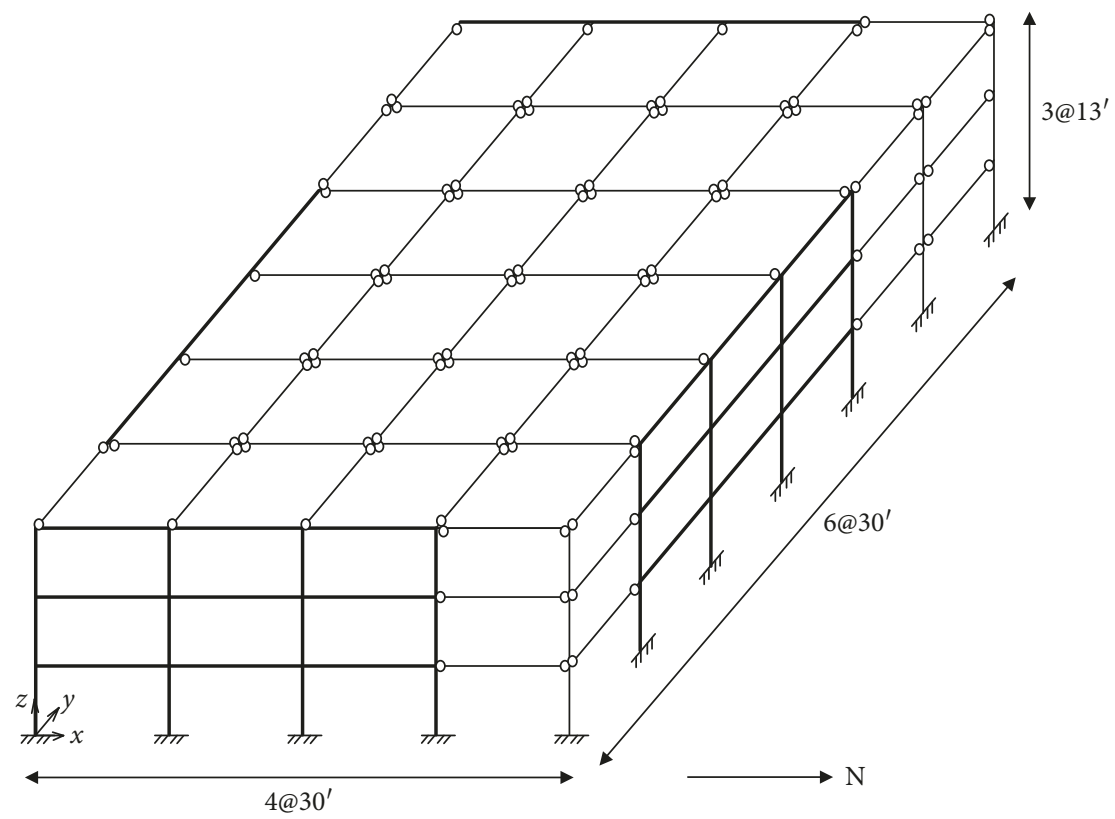

FIgURE 1: Isometric view of the 3-level building.

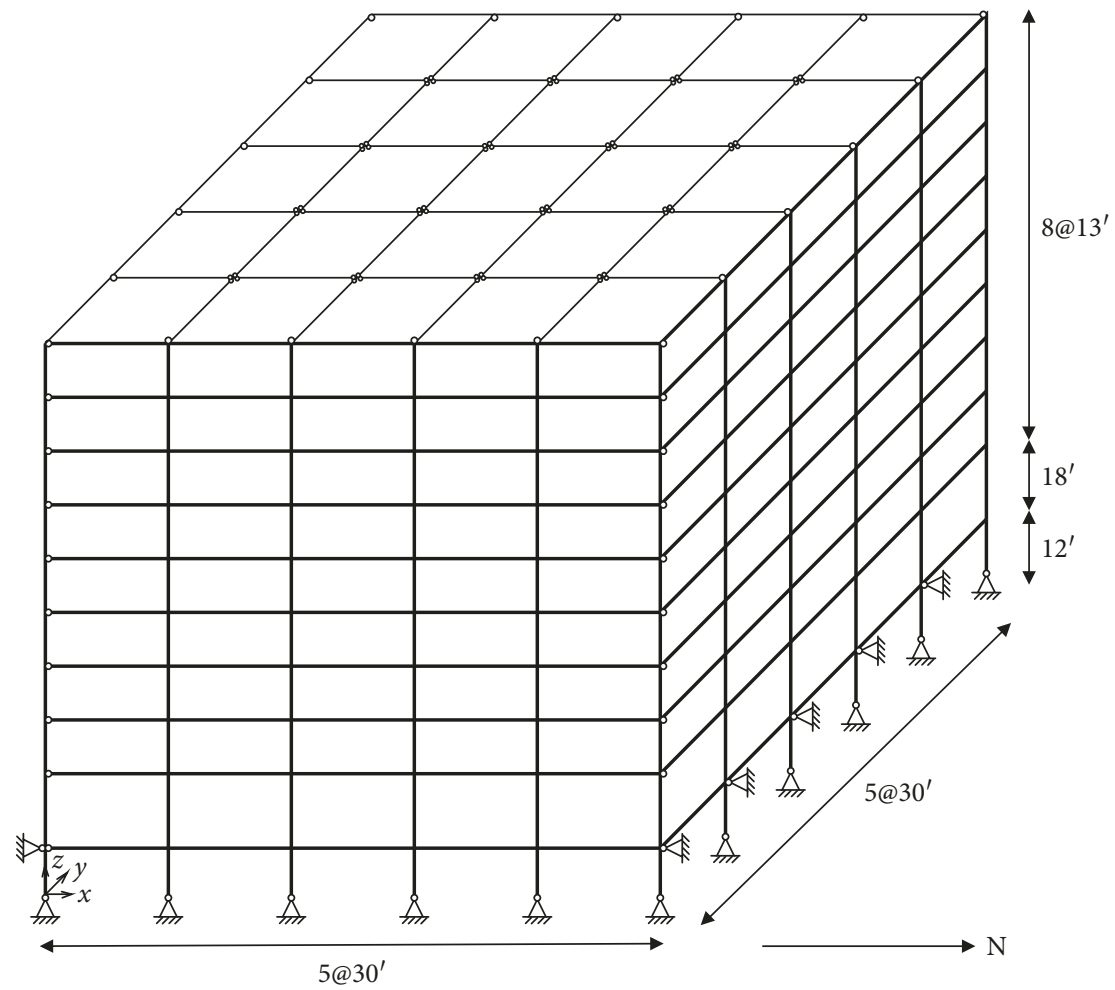

Figure 2: Isometric view of the 10-level building.

periods of the plane frames (lateral vibrations) are $1.03 \mathrm{~s}, 0.30 \mathrm{~s}$, and $0.15 \mathrm{~s}$, for the 3-level model; the corresponding values for the 10-level model are $2.41 \mathrm{~s}, 0.89 \mathrm{~s}$, and $0.5 \mathrm{~s}$. The damping is considered to be $3 \%$ of the critical. Each column is represented by one element and each girder by two elements, having a node at the midspan. The RUAUMOKO software [52] is used to perform the required step-by-step nonlinear seismic analysis.
It is worth to mention that some results of the SAC Steel Project are given in a research report [50] where many aspects of the seismic performance of the mentioned steel frame models subjected to earthquake ground motions are presented. The strong motions were scaled according to several return periods; story drifts of about $1 \%, 2 \%, 3 \%$, and $4 \%$ and a little larger (between 5\% and 6\%) were developed in the models. 
TABle 1: Beam and columns sections for Models 1 and 2.

\begin{tabular}{|c|c|c|c|c|}
\hline \multirow{2}{*}{ Model } & \multirow{2}{*}{ Story } & \multicolumn{2}{|l|}{ Columns } & \multirow{2}{*}{ Girder } \\
\hline & & Exterior & Interior & \\
\hline \multirow{3}{*}{1} & $1 \backslash 2$ & W14X257 & W14X311 & W33X118 \\
\hline & $2 \backslash 3$ & W14X257 & W14X312 & W30X116 \\
\hline & $3 \backslash \mathrm{ROOF}$ & W14X257 & W14X313 & W24X68 \\
\hline \multirow{10}{*}{2} & $-1 / 1$ & W14X370 & W14X500 & W36X160 \\
\hline & $1 / 2$ & W14X370 & W14X500 & W36X160 \\
\hline & $2 / 3$ & W14X370 & $\begin{array}{l}\text { W14X500, } \\
\text { W14X455 }\end{array}$ & W36X160 \\
\hline & $3 / 4$ & W14X370 & W14X455 & W36X135 \\
\hline & $4 / 5$ & W14X370,W14X283 & $\begin{array}{l}\text { W14X455, } \\
\text { W14X370 }\end{array}$ & W36X135 \\
\hline & $5 / 6$ & W14X283 & W14X370 & W36X135 \\
\hline & $6 / 7$ & W14X283,W14X257 & $\begin{array}{l}\text { W14X370, } \\
\text { W14X283 }\end{array}$ & W36X135 \\
\hline & $7 / 8$ & W14X257 & W14X283 & W30X99 \\
\hline & $8 / 9$ & W14X257,W14X233 & $\begin{array}{l}\text { W14X283, } \\
\text { W14X257 }\end{array}$ & W27X84 \\
\hline & 9/ROOF & W14X233 & $\mathrm{W} 14 \mathrm{X} 257$ & W24X68 \\
\hline
\end{tabular}

The frames are modeled as complex 2D MDOF systems, having three degrees of freedom per node. The Newmark constant average acceleration method, lumped mass matrix, Rayleigh damping, and large displacement effects are considered within the Ruaumoko Computer Program environment while performing the required nonlinear seismic analysis; the time increment in the analysis was $0.01 \mathrm{~s}$. The panel zone was considered to be rigid. Typical input data as ground accelerations, boundary conditions, node coordinates, and elastic and inelastic section properties are given or read within the computer program. No strength degradation member, bilinear behavior with $5 \%$ of the initial stiffness in the second zone, and concentrated plasticity were assumed. The interaction axial load-bending moment is given by the yield interaction surface proposed by Chen and Atsuta [53].

3.2. Earthquake Loading. When a structure is subjected to the action of two different strong motions, even when they are normalized with respect to the same peak ground acceleration or with respect to any other parameter, it is expected to respond differently, reflecting the influence of the frequency content of the motions and of the structural vibration modes. Thus, to get meaningful results, the models under consideration are excited by twenty strong motions in time domain whose characteristics are given in Table 2. The predominant periods of the strong motions range from 0.11 to $0.62 \mathrm{sec}$. The earthquake time histories were obtained from the Data Sets of the National Strong Motion Program (NSMP) of the United States Geological Surveys (USGS). For a given direction, half of the seismic loading and the tributary gravity loading are assigned to the corresponding PMRF. In order to have different levels of structural deformation as well as moderate and significant nonlinear behavior, the strong motions are scaled in terms of $S_{\text {a }}$ evaluated at the fundamental lateral vibration period $\left(S_{\mathrm{a}}\left(T_{1}\right)\right)$ ranging from $0.4 \mathrm{~g}$ to $1.2 \mathrm{~g}$ for the 3-level model and from $0.2 \mathrm{~g}$ to $0.6 \mathrm{~g}$ for the 10 -level model, with increments of $0.2 \mathrm{~g}$. Therefore, the maximum values of the seismic intensities are $S_{\mathrm{a}}=1.2 \mathrm{~g}$ and $0.6 \mathrm{~g}$ for the 3- and 10-level models, respectively. Thus, considering two models, twenty strong motions, two horizontal seismic components, and six seismic intensities, in addition to the elastic analyses, more than one thousand of nonlinear analyses of MDOF systems were performed.

The abovementioned maximum levels of seismic intensities produce a deformation state which is very close to that of a collapse mechanism, where interstory drifts of about $5 \%$ were developed for some strong motions; therefore, they are associated with the structural and ductility capacity. This is concordant with the results of some experimental studies where it has been shown that momentresisting steel frames may undergo interstory displacements of up to 5\% (and even larger) and still be able to vibrate in a stable manner [54-58]. Thus, the ductility values obtained for this level of deformation, according to the different definitions, are assumed to be the ductility capacity.

It is important to note that UBC-1994 in Sections 1629.1 and 1629.2 states: "Dynamic analysis procedures, when used, shall conform to the criteria established in this section. The analysis shall be based on an appropriate ground motion representation....The ground motions representation shall, as a minimum, be one having a $10 \%$ probability of being exceeded in 50\%...." The expression "as a minimum" implies that larger intensities (and larger drifts) of the strong motions can be used. In addition, according to the particular objectives stated in our paper, we need a deformation state close to that of a collapse mechanism which is developed for drifts of about $5 \%$, for some strong motions.

In addition to the seismic loading, the following gravity loads [50] were used in the analysis: (a) the floor dead load for weight calculations was $96 \mathrm{psf}$; (b) the floor dead load for mass calculations was $86 \mathrm{psf}$; (c) the roof dead load was $83 \mathrm{psf}$; (d) the reduced live load per floor and for roof was 20 psf. The seismic mass for the entire structure was as follows: (a) for the roof of the 3-level building, it was 70.90 kips- $\sec ^{2} / \mathrm{ft}$; (b) for floor 2 of the 3-level building, it was 65.53 kips- $\sec ^{2} / \mathrm{ft}$; (c) for the roof of the 10-level building, it was $73.10 \mathrm{kips}-\mathrm{sec}^{2} / \mathrm{ft}$; (d) for floor 2 of the 10-level building, it was $69.04 \mathrm{kips}-\mathrm{sec}^{2} / \mathrm{ft}$; (e) for floors 3 to 9 of the 10-level building, it was $67.86 \mathrm{kips}-\mathrm{sec}^{2} / \mathrm{ft}$.

3.3. Ductility Definitions. The discussions made in Sections 1 and 2 clearly indicate that the parameter ductility is a concept of central importance in seismic analysis and design of steel buildings. In this regard, the different types of ductility existing in a steel building must be considered [10]. Within a SDOF system context, ductility is defined as the ratio of the maximum inelastic displacement $\left(D_{\max }\right)$ to the yield displacement $\left(D_{\mathrm{y}}\right) . D_{\max }$ is calculated as the maximum displacement that the system undergoes during the application of the seismic loading and $D_{\mathrm{y}}$ as the displacement of the system when yielding occurs on it for the first time. For MDOF systems, however, it is not clearly stated how to define these two parameters $\left(D_{\max }\right.$ and $\left.D_{\mathrm{y}}\right)$; in addition, and 
TABLE 2: Earthquake records, N-S component.

\begin{tabular}{|c|c|c|c|c|c|c|c|}
\hline No & Place & Date & Station & $T_{\mathrm{n}}(\mathrm{sec})$ & $\mathrm{ED}(\mathrm{km})$ & $M$ & PGA $\left(\mathrm{cm} / \mathrm{sec}^{2}\right)$ \\
\hline 1 & Landers, California & $28 / 06 / 1992$ & Fun Valley, Reservoir 361 & 0.11 & 31 & 7.3 & 213 \\
\hline 2 & Mammoth Lakes, California & $27 / 05 / 1980$ & Convict Creek & 0.16 & 12 & 6.3 & 316 \\
\hline 3 & Victoria & $09 / 06 / 1980$ & Cerro Prieto & 0.16 & 37 & 6.1 & 613 \\
\hline 4 & Parkfield, California & $28 / 09 / 2004$ & Parkfield; Joaquin Canyon & 0.17 & 15 & 6.0 & 609 \\
\hline 5 & Puget Sound, Washington & $29 / 04 / 1965$ & Olympia Hwy Test Lab & 0.17 & 89 & 6.5 & 216 \\
\hline 6 & Long Beach, California & $10 / 03 / 1933$ & Utilities Bldg, Long Beach & 0.20 & 29 & 6.3 & 219 \\
\hline 7 & Sierra El Mayor, Mexico & $04 / 04 / 2010$ & El centro, California & 0.21 & 77 & 7.2 & 544 \\
\hline 8 & Petrolia/Cape Mendocino, California & 25/04/1992 & Centerville Beach, Naval Facility & 0.21 & 22 & 7.2 & 471 \\
\hline 9 & Morgan Hill & $24 / 04 / 1984$ & Gilroy Array Sta \#4 & 0.22 & 38 & 6.2 & 395 \\
\hline 10 & Western Washington & $13 / 04 / 1949$ & Olympia Hwy Test Lab & 0.22 & 39 & 7.1 & 295 \\
\hline 11 & San Fernando & $09 / 02 / 1971$ & Castaic-Old Ridge Route & 0.23 & 24 & 6.6 & 328 \\
\hline 12 & Mammoth Lakes, California & $25 / 05 / 1980$ & Long Valley Dam & 0.24 & 13 & 6.5 & 418 \\
\hline 13 & El Centro & $18 / 05 / 1940$ & El Centro-ImpVall Irr Dist & 0.27 & 12 & 7.0 & 350 \\
\hline 14 & Loma Prieta, California & $18 / 10 / 1989$ & Palo Alto & 0.29 & 47 & 6.9 & 378 \\
\hline 15 & Santa Barbara, California & $13 / 08 / 1978$ & UCSB Goleta FF & 0.36 & 14 & 5.1 & 361 \\
\hline 16 & Coalinga, California & $02 / 05 / 1983$ & Parkfield Fault Zone 14 & 0.39 & 38 & 6.2 & 269 \\
\hline 17 & Imperial Valley, California & $15 / 10 / 1979$ & Chihuahua & 0.40 & 19 & 6.5 & 262 \\
\hline 18 & Northridge, California & $17 / 01 / 1994$ & Canoga Park, Santa Susana & 0.60 & 16 & 6.7 & 602 \\
\hline 19 & Offshore Northern, California & $10 / 01 / 2010$ & Ferndale, California & 0.61 & 43 & 6.5 & 431 \\
\hline 20 & Joshua Tree, California & $23 / 04 / 1992$ & Indio, Jackson Road & 0.62 & 26 & 6.1 & 400 \\
\hline
\end{tabular}

as commented above, it is necessary to properly consider the different levels of ductility (local, story, and global). It is generally accepted that local ductility is larger than story ductility, which in turn is larger than global ductility. It must be noted that ductility demand is different from ductility capacity. For example, for the case of a particular story, story ductility demand can be defined as the ratio of the maximum relative lateral displacement (drift) of the story during the application of the seismic loading to the corresponding drift when first yielding occurs at any member of the story, while ductility capacity is the ratio of the maximum permissible inelastic drift to the drift when first yielding occurs. Ductility capacity is usually obtained from experimental results for individual members (local ductility). For that reason, some researchers [59] suggest using local ductility as the basis for design because there are numerous laboratory studies on ductility for members. Therefore, it is important to relate the local to the story, or to the overall structural ductility (global ductility).

Theoretically, ductility capacity should be reached when a collapse mechanism develops in the structure. To obtain this, it needs to be guaranteed that plastic moments are reached at positions of maximum moments before failure due to instability, namely, local buckling or lateral torsional buckling, in a member or in a connection occurs. For the case of steel buildings, local ductility $\left(\mu_{\mathrm{L} \phi}\right)$ for a flexural member will be associated with the rotational deformation of the member. It is defined, for a given joint, as the ratio of the maximum inelastic curvature that the joint undergoes during the total time of excitation $\left(\phi_{\max }\right)$ to the curvature of the joint when it yields for the first time $\left(\phi_{\mathrm{y}}\right)$. Mathematically, it is expressed as

$$
\mu_{\mathrm{L} \phi}=\frac{\phi_{\max }}{\phi_{y}}
$$

Thus, as soon as any of the joints of a given member yields for the first time, the corresponding curvature is identified as $\phi_{\mathrm{y}}$ for that particular member. In a similar manner, the curvature is calculated at each time increment of the analysis, and the largest one is identified as $\phi_{\max }$ for the node and member under consideration. This type of ductility demand will be calculated for beams as well as for those columns where plasticization is produced mainly by bending moments; as it will be further discussed below this is the case for most columns, particularly for the 10-level building.

Story ductility is defined in terms of lateral drifts. The ductility of a story $\left(\mu_{\mathrm{S}}\right)$ is defined as the ratio of the maximum inelastic drift of the story during the total time of excitation $\left(\Delta_{\max }\right)$ to the drift of the story when any of its members yields for the first time $\left(\Delta_{\mathrm{y}}\right)$. Mathematically, we have

$$
\mu_{\mathrm{S}}=\frac{\Delta_{\max }}{\Delta_{\mathrm{y}}}
$$

Regarding the $\Delta_{\mathrm{y}}$ parameter in Equation (2), it is assumed that, for a given story, the beams and columns connecting beneath it are part of the story. For example, for the 3-story model (top story), going from the top to the bottom, the first three beams and four columns are considered to be part of the third story; in the same manner, the second set of three beams and four columns are considered to be part of Story 2, and so on. Then, in the $\mu_{\mathrm{S}}$ definition, the expression "the drift of the story when any of its members yields for the first time" refers to first yielding of any beam or column that is part of the story under consideration.

Since global ductility should represent the overall structural inelastic deformation, some researchers suggest defining it in terms of relative lateral displacements $[5,10,58]$. Here, it is defined as the mean value of the story ductilities; mathematically, we have 


$$
\mu_{\mathrm{G}}=\frac{1}{n} \sum_{i=1}^{n}\left(\mu_{\mathrm{S}}\right)_{i},
$$

where $n$ is the number of stories.

3.4. Ductility Reduction Factor. As for the ductility parameter, the ductility reduction factors are estimated for different structural levels. This parameter, in general, can be expressed as

$$
R_{\mu}=\frac{R_{\mathrm{e}}}{R_{i}},
$$

where $R_{\mathrm{e}}$ represents the peak value of a given, local, story, or global response parameter, obtained from elastic analyses (without considering dissipation of energy) and $R_{\mathrm{i}}$ represents the same, but nonlinear analyses (considering dissipation of energy) are considered instead. For the case of bending moments, which is a local response parameter, Equation (4) takes the following particular form:

$$
R_{\mu \mathrm{L} \phi}=\frac{M_{\mathrm{e}}}{M_{\mathrm{i}}},
$$

where $R_{\mu \mathrm{L} \phi}$ is the bending local ductility reduction factor and $M_{\mathrm{e}}$ and $M_{\mathrm{i}}$ are the elastic and inelastic peak bending moments, respectively, at a given joint of a given member. Equation (5) will be used to calculate the reduction in bending moments for both beam and columns. Reductions in axial loads on columns are not calculated since, as stated above, the number of cases where dissipation of energy due to plasticization by the axial load occurs is very small in comparison with that of bending moments.

The story ductility reduction factor $\left(R_{\mu \mathrm{S}}\right)$ is calculated as

$$
R_{\mu \mathrm{S}}=\frac{V_{\mathrm{se}}}{V_{\mathrm{si}}},
$$

where $V_{\text {se }}$ and $V_{\text {si }}$ are the elastic and inelastic peak values of the interstory shears, respectively. The global ductility reduction factors $\left(R_{\mu \mathrm{G}}\right)$ are calculated as the mean values of $R_{\mu \mathrm{S}}$, and it is

$$
R_{\mu \mathrm{G}}=\frac{1}{n} \sum_{i=1}^{n}\left(R_{\mu \mathrm{S}}\right)_{i} .
$$

3.5. Dissipated Energy. The dissipated energy is also calculated for local, story, and global levels. The normalized dissipated energy at a given joint $\left(E_{\mathrm{L} \phi}\right)$ of a given beam is calculated as

$$
E_{\mathrm{L} \phi}=\frac{E_{\mathrm{D} \phi}}{E_{\mathrm{C} \phi}},
$$

where $E_{\mathrm{D} \phi}$ is the energy demand and $E_{\mathrm{C} \phi}$ is the energy capacity of a member under the action of only bending moment. $E_{\mathrm{C} \phi}$ in Equation (8) is estimated by the following equation $[60,61]$ :

$$
E_{\mathrm{C} \phi}=M_{\mathrm{P}} \theta_{\mathrm{pa}},
$$

where $M_{\mathrm{P}}$ and $\theta_{\mathrm{pa}}$ in Equation (9) in turn represent the plastic moment and the cumulative plastic rotation capacity of a member under bending, respectively. Even though experiments to estimate the $\theta_{\text {pa }}$ parameter are not common, there is some experimental evidence to provide a reasonable value. A value of 0.23 for $\theta_{p a}$ will be used in this paper [60-65].

For all the beams of a story, the average normalized dissipated energy per joint $\left(\left(E_{\mathrm{L} \phi}\right)_{\mathrm{SB}}\right)$ can be calculated as

$$
\left(E_{\mathrm{L} \phi}\right)_{\mathrm{SB}}=\frac{1}{2 q} \sum_{j=1}^{2 q}\left(E_{L \phi}\right)_{j},
$$

where $q$ is the number of beams in the story.

The normalized dissipated energy by bending at a column $\left(E_{\mathrm{L} \phi}^{*}\right)$ is calculated as

$$
E_{\mathrm{L} \phi}^{*}=\frac{E_{\mathrm{D} \phi}}{E_{\mathrm{C} \phi}^{*}},
$$

where $E_{\mathrm{C} \phi}^{*}$ is the reduced energy capacity of a column due to the presence of axial loads. Taking into account that (a) the SC-WB concept was followed in the design of the structural models implying that most of the hysteretic dissipated energy will occur in beams by the action of bending moments, (b) experimental studies regarding the cumulative plastic rotation capacity of a member under the combined action of bending moment and axial load are rare, and (c) the level of average axial load demands observed in this study implies a reduction of the bending moment capacity in columns of about $30-50 \%$, it is conservatively assumed in this research that the cumulative plastic rotation capacity of a member under the action of bending and axial load is one third of that of $\theta_{\mathrm{pa}}$. Then,

$$
E_{\mathrm{C} \phi}^{*}=\frac{1}{3}\left(M_{\mathrm{P}} \theta_{\mathrm{pa}}\right) .
$$

For all the columns of a story, it is obtained as

$$
\left(E_{\mathrm{L} \phi}^{*}\right)_{\mathrm{SC}}=\frac{1}{2 r} \sum_{k=1}^{2 r}\left(E_{\mathrm{L} \phi}^{*}\right)_{k},
$$

where $\left(E_{\mathrm{L} \phi}^{*}\right)_{\mathrm{SC}}$ is the normalized energy per joint and $r$ is the number of columns. The average normalized dissipated energy per joint in a given story $\left(E_{\mathrm{S}}\right)$ is calculated as

$$
E_{\mathrm{S}}=\frac{1}{(2 q+2 r)}\left(\sum_{j=1}^{2 q}\left(E_{\mathrm{L} \phi}\right)_{j}+\sum_{k=1}^{2 r}\left(E_{\mathrm{L} \phi}^{*}\right)_{k}\right) .
$$

Finally, the normalized dissipated energy for the whole frame $\left(E_{\mathrm{G}}\right)$ is calculated as

$$
E_{\mathrm{G}}=\frac{1}{n} \sum_{i=1}^{n}\left(E_{\mathrm{s}}\right)_{i} .
$$

All the parameters in Equation (15) were defined earlier. 


\section{Results and Discussion}

\subsection{Objective 1: Results in Terms of Ductility}

4.1.1. Local Ductility. The bending local ductility parameter (Equation (1)) is calculated for each individual beam and columns of the two models for the seismic intensities of each strong motion mentioned in Section 3.2. First, the models are subjected to the simultaneous action of the horizontal seismic component oriented in the NS direction, the vertical seismic component, and the gravity loads. Then, the models are subjected to a similar set of loads, but the other horizontal (EW) seismic component is applied instead. It is assumed in this research that structural members have no problems of lateral torsional and local or shear buckling in the panel zone. As stated above in Section 3.3, bending local ductilities are expressed in terms of curvatures in this paper. Local ductilities expressed in terms of rotations are expected to be smaller.

For a given story, the $\mu_{\mathrm{L} \phi}$ values are averaged, first over all the beams (Equations (10)), and then over all the columns (Equations (12)). It must be noted that even though the SC-WB concept was followed in the model design, plastic hinges were developed in some columns, particularly for the 10-level model and the largest intensity of the strong motions. Plots for the resulting averages are developed for each strong motion, but they are not presented, about 30 plots were developed. Only the fundamental statistics in terms of the mean values (MV), calculated over all the strong motions, are given. The results are presented in Table 3 for the 3 -level model and in Figures 3(a)-3(d) for the 10-level model. The term "ST" in the table and in figures stands for the story level. Results indicate that, for the beams of the 3-level building, the maximum bending ductility demands occur, in general, for the second story. For the case of columns, unlike what observed for beams, the mean values of $\mu_{\mathrm{L} \phi}$ tend to decrease with the story number, but the mean values are much smaller than those of beams; in fact, for the two lowest intensities $\left(S_{\mathrm{a}}=0.4 \mathrm{~g}\right.$ and $\left.0.6 \mathrm{~g}\right)$, they are essentially equal to unity for the two upper stories implying no yielding. For both, beams and columns, the mean values tend to increase with the seismic intensity and are larger for the NS than that for the EW direction. The largest observed values for beams are 11.86 and 9.32 for the NS and $\mathrm{EW}$ direction, respectively.

The results for the 10-level building resemble those of the 3-level building in the sense that the mean values of $\mu_{\mathrm{L} \phi}$ are much larger for beams than for columns. However, unlike the 3-level building, the mean values tend to decrease with the story number for beams, and as for the 3-story building, the $\mu_{\mathrm{L} \phi}$ mean values tend to decrease with the story number for columns. No yielding occurs in columns in most of the cases for the two lowest intensities of the strong motions $\left(S_{\mathrm{a}}=0.2 \mathrm{~g}\right.$ and $\left.0.4 \mathrm{~g}\right)$. The only additional observation that can be made is that, for the larger strong motion intensities, the maximum mean values of the bending local ductility demands for beams are larger for the 10-level building than that for the 3-level building (14.3 against 11.86).
It is worth to mention that moderate yielding occurred for seismic intensities of $0.4 \mathrm{~g}$ and $0.2 \mathrm{~g}$ for the 3 - and 10 level structural models, respectively; the corresponding seismic intensities for significant deformation, as stated in Section 3.2, are $1.2 \mathrm{~g}$ and $0.6 \mathrm{~g}$, for the 3 - and 10 -level models, respectively. Even though, it is not shown in the paper, the drifts for these significant levels of deformation were about $5 \%$ for many of the strong motions. Thus the mean values of $\mu_{\mathrm{L} \phi}$ shown in Table 3, or in Figures 3(a)-3(d), are associated with the structural capacity and are assumed to be the bending local ductility capacity. Even though, as stated earlier, results for individual strong motions are not included in the paper, it was observed that the maximum values of $\mu_{\mathrm{L} \phi}$ were close to 20 for some particular earthquake and stories. There is some evidence in the literature [10,66-68] that the bending local ductility capacity can reach values larger than 20; however, it was for monotonic loading and individual members. It was also observed that, for a given value of $S_{\mathrm{a}}$, the magnitude of $\mu_{\mathrm{L} \phi}$ significantly varies from one seismic motion to another, in spite of the structural deformation, in terms of $S_{\mathrm{a}}$ for each seismic motion was the same, reflecting the effect of the frequency content on the values of the $\mu_{\mathrm{L} \phi}$ parameter. The coefficients of variation (COV) are not shown either, but it can be said that the uncertainty in the estimation of $\mu_{\mathrm{L} \phi}$ is moderated in most of the cases (COV 0.20-0.45).

4.1.2. Story Ductility. Similar to the $\mu_{\mathrm{L} \phi}$ parameter, the $\mu_{\mathrm{S}}$ values as defined by Equation (2) are calculated for both structural models and horizontal directions, and plots for individual strong motions are developed but are not presented. The mean values for all seismic intensities and structural directions are presented in Table 4 and Figures 4(a) and 4(b), for the 3- and 10-level buildings, respectively. It can be observed that, similar to $\mu_{\mathrm{L} \phi}$ for beams, the mean values of $\mu_{\mathrm{S}}$ do not present any tendency with the story number for the case of the 3-level building; for the 10level building, however, unlike the case of $\mu_{\mathrm{L} \phi}$, the values do not tend to decrease with height. By comparing the results of Table 3 and Figures 3(a)-3(d) with those of Table 4 and Figures $4(\mathrm{a})$ and $4(\mathrm{~b})$, it is observed that, for beams, $\mu_{\mathrm{S}}$ is much smaller than $\mu_{\mathrm{L} \phi}$; the mean values for the maximum seismic intensity range from 3.84 to 4.28 and from 2.49 to 5.19 , for the 3 - and 10-level models, respectively. Both, $\mu_{\mathrm{L} \phi}$ and $\mu_{\mathrm{S}}$ mean values for beams tend to increase with the seismic intensity.

4.1.3. Global Ductility. The global ductility values $\left(\mu_{\mathrm{G}}\right)$ are now discussed. The results are given in Table 5 for the two buildings, the two horizontal directions, and all seismic intensities. It can be observed that the mean values of $\mu_{\mathrm{G}}$ tend to increase (as expected) with the strong motion intensity and that they are quite similar for the two buildings; for the demands associated with the maximum deformations (ductility capacity), $\mu_{\mathrm{G}}$ takes values of 3.95 and 3.89 , for the NS and EW directions, respectively, for the 3-level building; the corresponding values are 4.11 and 3.60 for the 10 -level 
TABLE 3: Mean values of $\mu_{\mathrm{L} \phi}, R_{\mu \mathrm{L} \phi}$, and $Q_{\mathrm{L}}$, 3-level building.

\begin{tabular}{|c|c|c|c|c|c|c|c|c|c|c|c|c|}
\hline \multirow{3}{*}{ Parameter } & \multirow{3}{*}{ Type of member } & \multirow{3}{*}{ ST } & \multirow{2}{*}{\multicolumn{5}{|c|}{$\begin{array}{l}\text { NS direction } \\
S_{\mathrm{a}} / \mathrm{g} \text { values }\end{array}$}} & \multirow{2}{*}{\multicolumn{5}{|c|}{$\begin{array}{c}\text { EW direction } \\
S_{\mathrm{a}} / \mathrm{g} \text { values }\end{array}$}} \\
\hline & & & & & & & & & & & & \\
\hline & & & 0.4 & 0.6 & 0.8 & 1.0 & 1.2 & 0.4 & 0.6 & 0.8 & 1.0 & 1.2 \\
\hline \multirow{6}{*}{$\mu_{\mathrm{L} \phi}$} & \multirow{3}{*}{ Beams } & 1 & 2.61 & 4.27 & 5.99 & 8.23 & 10.22 & 2.19 & 3.56 & 4.56 & 6.33 & 7.81 \\
\hline & & 2 & 2.48 & 4.60 & 7.17 & 9.57 & 11.86 & 2.26 & 4.15 & 5.87 & 7.69 & 9.32 \\
\hline & & 3 & 2.01 & 4.31 & 6.71 & 8.94 & 11.20 & 1.99 & 3.73 & 5.59 & 7.67 & 9.30 \\
\hline & \multirow{3}{*}{ Columns } & 1 & 1.06 & 1.32 & 1.95 & 2.65 & 3.70 & 1.01 & 1.25 & 1.72 & 2.22 & 2.87 \\
\hline & & 2 & 1.00 & 1.00 & 1.09 & 1.25 & 1.41 & 1.00 & 1.01 & 1.03 & 1.21 & 1.29 \\
\hline & & 3 & 1.00 & 1.00 & 1.06 & 1.12 & 1.23 & 1.00 & 1.00 & 1.02 & 1.13 & 1.26 \\
\hline \multirow{6}{*}{$R_{\mu \mathrm{L} \phi}$} & \multirow{3}{*}{ Beams } & 1 & 1.68 & 2.29 & 2.89 & 3.45 & 4.06 & 1.54 & 2.12 & 2.68 & 3.22 & 3.91 \\
\hline & & 2 & 1.66 & 2.25 & 2.79 & 3.28 & 3.86 & 1.55 & 2.11 & 2.65 & 3.16 & 3.81 \\
\hline & & 3 & 1.58 & 2.11 & 2.60 & 3.06 & 3.60 & 1.50 & 2.01 & 2.50 & 2.97 & 3.54 \\
\hline & \multirow{3}{*}{ Columns } & 1 & 1.52 & 1.87 & 2.25 & 2.60 & 2.98 & 1.35 & 1.66 & 2.00 & 2.35 & 2.79 \\
\hline & & 2 & 1.50 & 1.85 & 2.19 & 2.51 & 2.86 & 1.37 & 1.71 & 2.01 & 2.32 & 2.71 \\
\hline & & 3 & 1.55 & 1.95 & 2.28 & 2.59 & 2.95 & 1.43 & 1.81 & 2.17 & 2.51 & 2.92 \\
\hline \multirow{6}{*}{$Q_{\mathrm{L}}$} & \multirow{3}{*}{ Beams } & 1 & 0.64 & 0.54 & 0.48 & 0.42 & 0.40 & 0.70 & 0.60 & 0.59 & 0.51 & 0.50 \\
\hline & & 2 & 0.67 & 0.49 & 0.39 & 0.34 & 0.33 & 0.69 & 0.51 & 0.45 & 0.41 & 0.41 \\
\hline & & 3 & 0.79 & 0.49 & 0.39 & 0.34 & 0.32 & 0.75 & 0.54 & 0.45 & 0.39 & 0.38 \\
\hline & \multirow{3}{*}{ Columns } & 1 & 1.43 & 1.42 & 1.15 & 0.98 & 0.81 & 1.34 & 1.33 & 1.16 & 1.06 & 0.97 \\
\hline & & 2 & 1.50 & 1.85 & 2.01 & 2.01 & 2.03 & 1.37 & 1.69 & 1.95 & 1.92 & 2.10 \\
\hline & & 3 & 1.55 & 1.95 & 2.15 & 2.31 & 2.40 & 1.43 & 1.81 & 2.13 & 2.22 & 2.32 \\
\hline
\end{tabular}

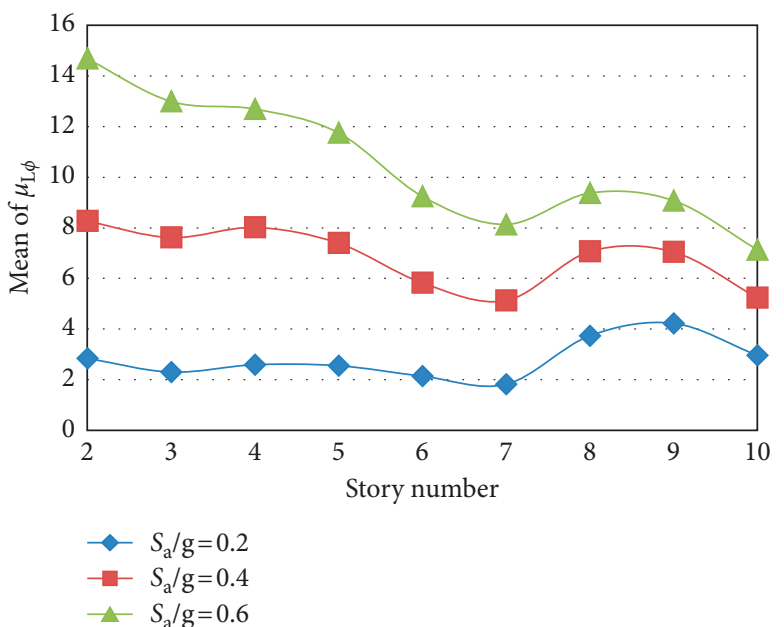

(a)

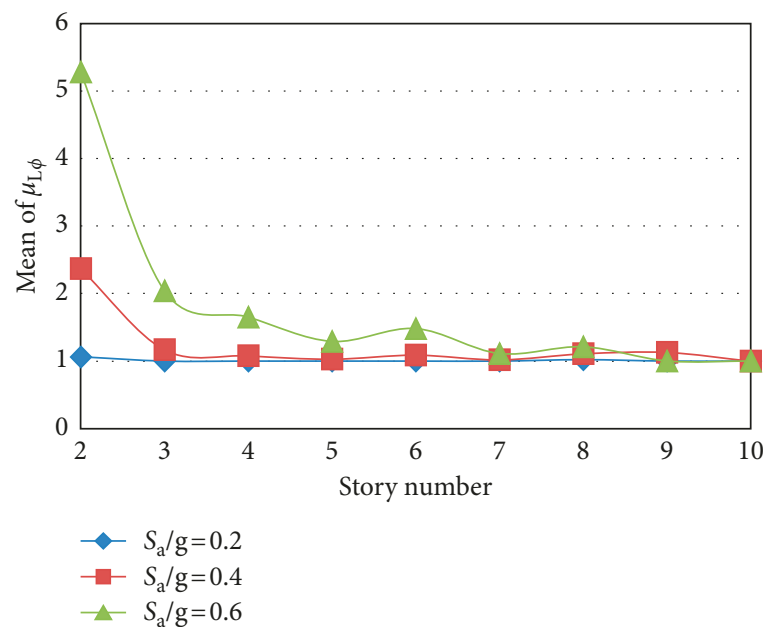

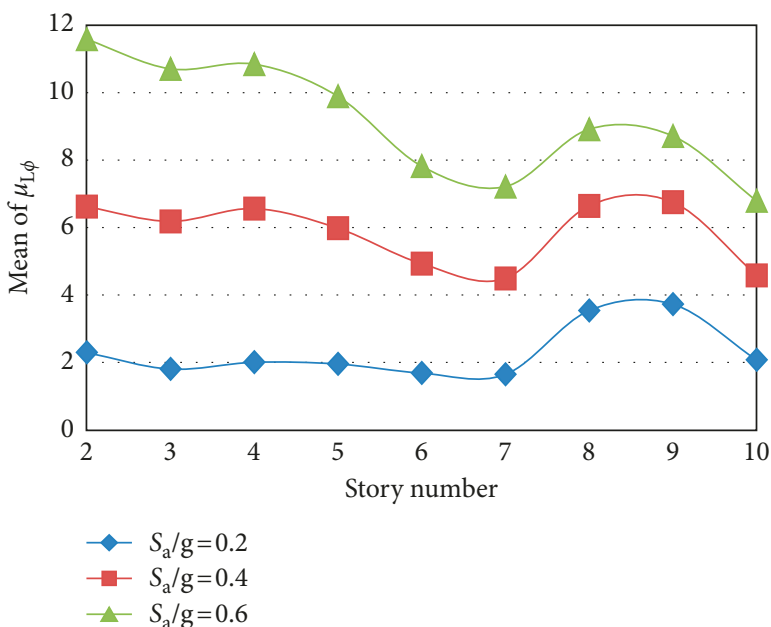

(b)

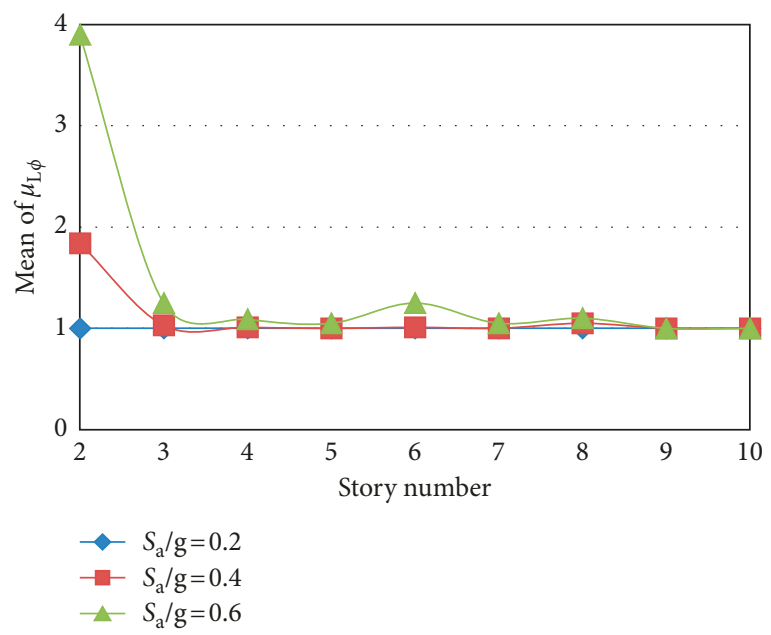

(d)

Figure 3: Continued. 


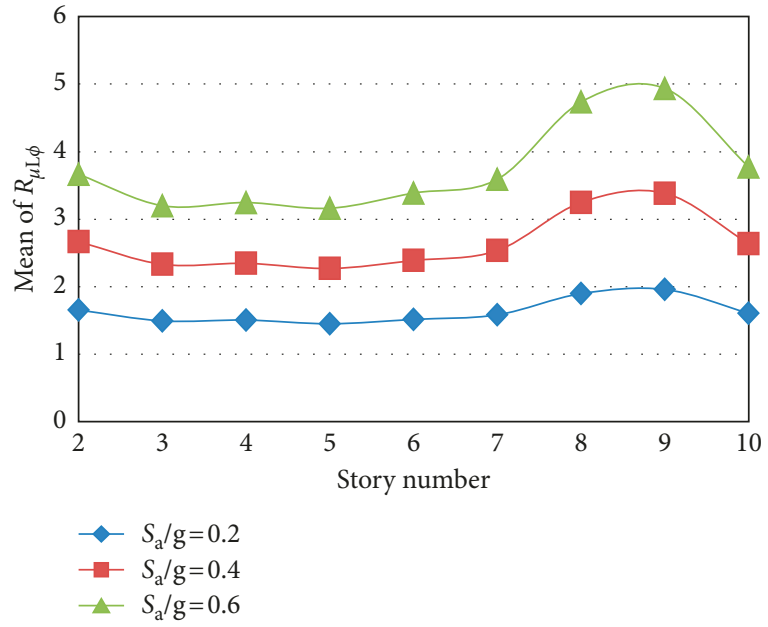

(e)

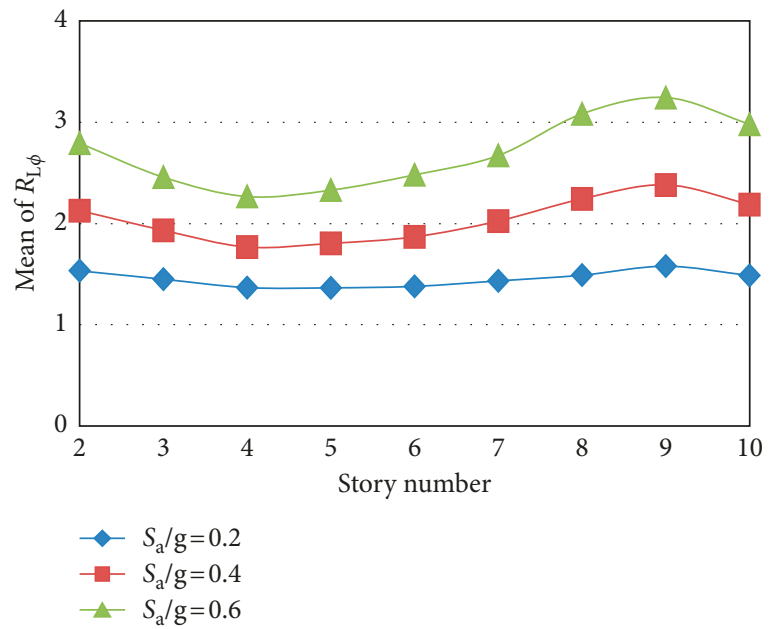

(g)

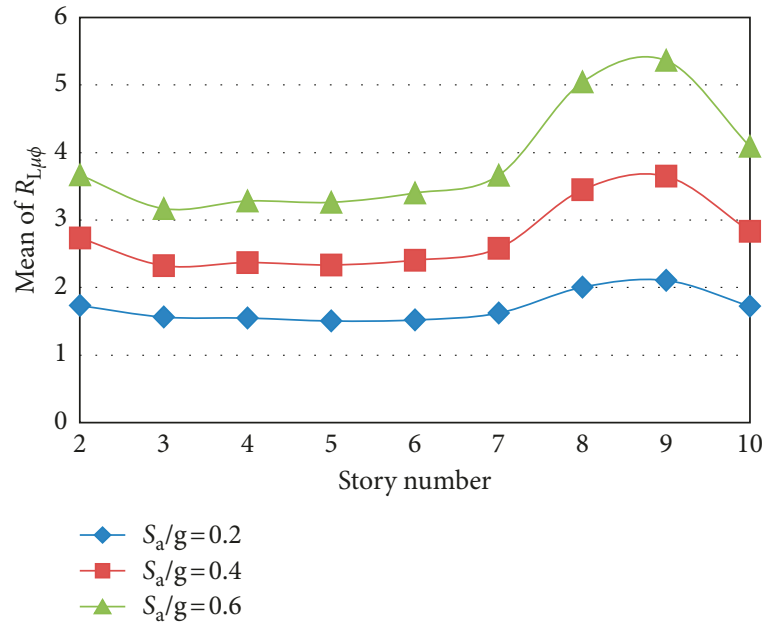

(f)

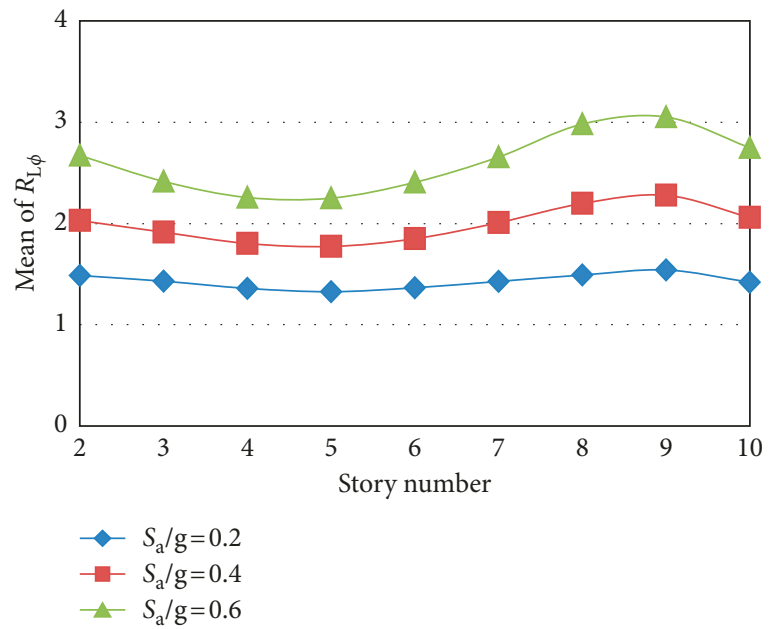

(h)

FIgUre 3: 10-level building. Mean values of $\mu_{\mathrm{L} \phi}$ : (a) beams NS; (b) beams EW; (c) columns NS; (d) columns EW. Mean values of $R_{\mu \mathrm{L} \phi}$ : (e) beams NS; (f) beams EW; (g) columns NS; (h) columns EW.

TABLE 4: Statistics for $\mu_{\mathrm{S}}, \mathrm{R}_{\mu \mathrm{S}}$, and $Q_{\mathrm{S}}$, 3-level building.

\begin{tabular}{|c|c|c|c|c|c|c|c|c|c|c|c|}
\hline \multirow{3}{*}{ Parameter } & \multirow{3}{*}{ ST } & \multirow{2}{*}{\multicolumn{5}{|c|}{$\begin{array}{l}\text { NS direction } \\
S_{\mathrm{a}} / \mathrm{g} \text { values }\end{array}$}} & \multirow{2}{*}{\multicolumn{5}{|c|}{$\begin{array}{c}\text { EW direction } \\
S_{\mathrm{a}} / \mathrm{g} \text { values }\end{array}$}} \\
\hline & & & & & & & & & & & \\
\hline & & 0.4 & 0.6 & 0.8 & 1.0 & 1.2 & 0.4 & 0.6 & 0.8 & 1.0 & 1.2 \\
\hline \multirow{3}{*}{$\mu_{\mathrm{S}}$} & 1 & 1.61 & 1.99 & 2.81 & 3.44 & 3.95 & 1.48 & 1.90 & 2.80 & 2.89 & 4.28 \\
\hline & 2 & 1.70 & 2.20 & 2.86 & 3.31 & 3.99 & 1.65 & 2.15 & 2.58 & 3.09 & 3.54 \\
\hline & 3 & 1.53 & 1.93 & 2.69 & 2.99 & 3.90 & 1.52 & 2.10 & 2.72 & 3.19 & 3.84 \\
\hline \multirow{3}{*}{$\mathrm{R}_{\mu \mathrm{S}}$} & 1 & 1.46 & 1.90 & 2.37 & 2.76 & 3.10 & 1.33 & 1.73 & 2.11 & 2.51 & 2.89 \\
\hline & 2 & 1.44 & 1.86 & 2.30 & 2.68 & 3.05 & 1.36 & 1.84 & 2.25 & 2.68 & 3.06 \\
\hline & 3 & 1.45 & 1.84 & 2.17 & 2.47 & 2.76 & 1.36 & 1.75 & 2.08 & 2.36 & 2.67 \\
\hline \multirow{3}{*}{$Q_{\mathrm{S}}$} & 1 & 0.91 & 0.95 & 0.84 & 0.80 & 0.78 & 0.90 & 0.91 & 0.75 & 0.87 & 0.68 \\
\hline & 2 & 0.85 & 0.85 & 0.80 & 0.81 & 0.76 & 0.82 & 0.86 & 0.87 & 0.87 & 0.86 \\
\hline & 3 & 0.95 & 0.95 & 0.81 & 0.83 & 0.71 & 0.89 & 0.83 & 0.76 & 0.74 & 0.70 \\
\hline
\end{tabular}

building. By comparing the results of Table 5 with those of $\mu_{\mathrm{L} \phi}$ for beams (Table 3 and Figures 3(a) and 3(b)), it is noted that, as for the case $\mu_{\mathrm{S}}$, the values are significantly smaller for $\mu_{\mathrm{G}}$.
4.1.4. Ratio of Local to Global Ductility. As stated above, the estimation of ductility capacity is commonly based on experimental studies of individual members. For this reason, it is suggested [59] considering local ductility as the basis for 


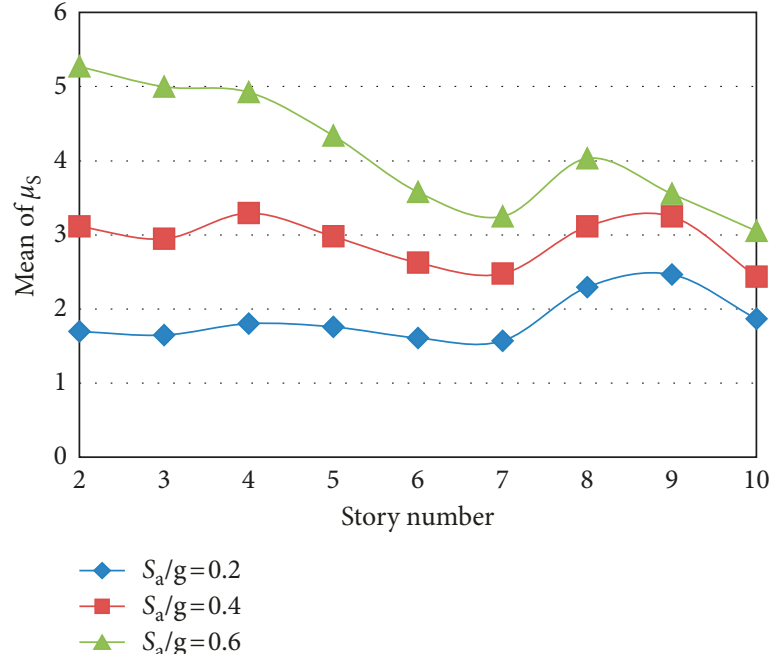

(a)

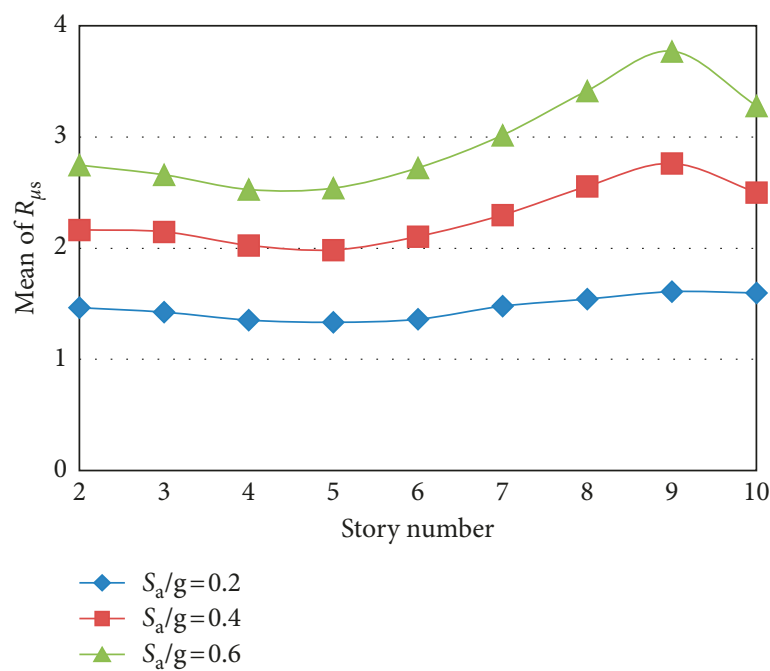

(c)

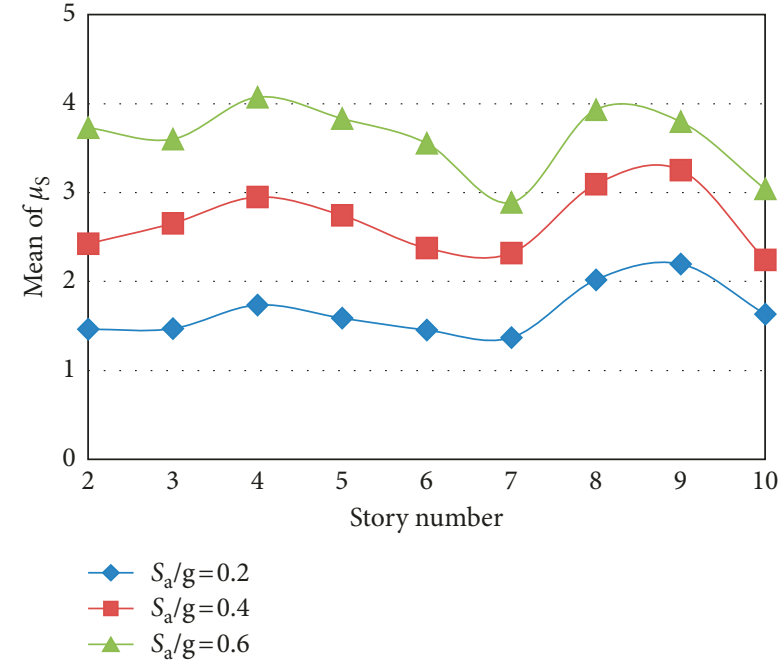

(b)

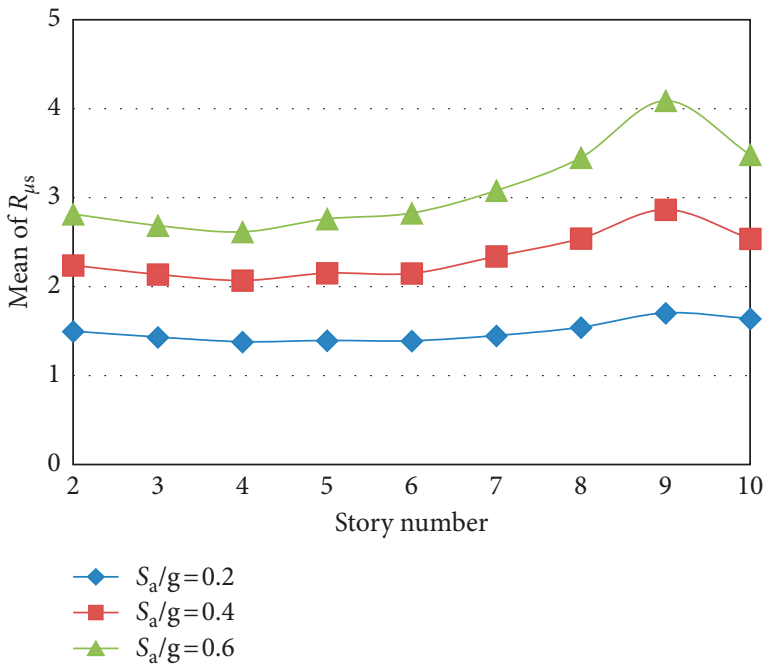

(d)

Figure 4: 10-level building. Mean values of $\mu_{\mathrm{S}}$ : (a) NS direction; (b) EW direction. Mean values of $R_{\mu \mathrm{S}}$ : (c) NS direction; (d) EW direction.

TABLE 5: Mean of $\mu_{\mathrm{G}}, Q, R_{\mu \mathrm{G}}$, and $Q_{\mathrm{G}}$ parameters, 3- and 10-level buildings.

\begin{tabular}{|c|c|c|c|c|c|c|c|c|c|c|c|c|c|c|c|c|}
\hline \multirow{4}{*}{ Parameter } & \multicolumn{10}{|c|}{ 3-level } & \multicolumn{6}{|c|}{ 10-level } \\
\hline & \multirow{2}{*}{\multicolumn{5}{|c|}{$\begin{array}{l}\text { NS direction } \\
S_{\mathrm{a}} / \mathrm{g} \text { values }\end{array}$}} & \multirow{2}{*}{\multicolumn{5}{|c|}{$\begin{array}{l}\text { EW direction } \\
S_{\mathrm{a}} / \mathrm{g} \text { values }\end{array}$}} & \multirow{2}{*}{\multicolumn{3}{|c|}{$\begin{array}{l}\text { NS direction } \\
S_{\mathrm{a}} / \mathrm{g} \text { values }\end{array}$}} & \multirow{2}{*}{\multicolumn{3}{|c|}{$\begin{array}{c}\text { EW direction } \\
S_{\mathrm{a}} / \mathrm{g} \text { values }\end{array}$}} \\
\hline & & & & & & & & & & & & & & & & \\
\hline & 0.4 & 0.6 & 0.8 & 1.0 & 1.2 & 0.4 & 0.6 & 0.8 & 1.0 & 1.2 & 0.2 & 0.4 & 0.6 & 0.2 & 0.4 & 0.6 \\
\hline$\mu_{\mathrm{G}}$ & 1.61 & 2.04 & 2.79 & 3.25 & 3.95 & 1.55 & 2.05 & 2.70 & 3.05 & 3.89 & 1.86 & 2.92 & 4.11 & 1.66 & 2.67 & 3.60 \\
\hline $\mathrm{Q}$ & 0.68 & 0.46 & 0.42 & 0.36 & 0.36 & 0.72 & 0.54 & 0.51 & 0.42 & 0.44 & 0.67 & 0.43 & 0.37 & 0.72 & 0.46 & 0.35 \\
\hline$R_{\mu \mathrm{G}}$ & 1.35 & 1.77 & 2.15 & 2.52 & 2.87 & 1.45 & 1.87 & 2.28 & 2.64 & 2.97 & 1.47 & 2.28 & 2.97 & 1.49 & 2.34 & 3.09 \\
\hline$Q_{\mathrm{G}}$ & 0.84 & 0.87 & 0.77 & 0.78 & 0.73 & 0.94 & 0.91 & 0.84 & 0.87 & 0.76 & 0.79 & 0.78 & 0.72 & 0.90 & 0.88 & 0.86 \\
\hline
\end{tabular}

design. In this regard, it is important to find a relationship $\left(Q=\mu_{\mathrm{G}} / \mu_{\mathrm{L} \phi}\right)$ between global and local ductility. The $\mu_{\mathrm{G}}$ values given in Table 5 and the $\mu_{\mathrm{L} \phi}$ values, averaged over all the beams of the frames, are used to calculate the $Q$ ratio. The results are summarized in the second row of Table 5. It is observed that the ratio values tend to decrease with the intensity of the earthquake. Based on the results obtained for the maximum deformation under consideration $(0.36,0.44$, 0.37 , and 0.35 ), a value of $1 / 3$ is proposed for the $Q$ ratio.

\subsection{Objective 2: Results for Ductility Reduction Factor}

4.2.1. Local Ductility Reduction Factor. The local, story, and global ductility reduction factors, as given by Equations 
(5)-(7), respectively, are now calculated. Bending local ductility reduction factors $\left(R_{\mu \mathrm{L} \phi}\right)$ is discussed first. As for the $\mu_{\mathrm{L} \phi}$ parameter, for a given story, the $R_{\mu \mathrm{L} \phi}$ values are averaged, first over all the beams, and then over all the columns. Plots for the resulting averages, as for the other parameters, are developed for individual strong motions, but they are not presented. Only the mean values are given and discussed. The results are presented in Table 3 for the 3-level model, while those of the 10-level building are given in Figures 3(e)-3(h).

It can be seen that, for beams of the 3-level building, the mean values of $R_{\mu \mathrm{L} \phi}$ tend to decrease with the story number but tend to increase with the seismic intensity, implying that the magnitude of the reduction of the bending moments of beams produced by yielding decreases with the story number, but it increases with the strong motion intensity. This variation with the story number is not observed for column moments; in fact, the maximum reductions occur for the upper level. It is also shown that the mean values of $R_{\mu \mathrm{L} \phi}$ are larger for beams than that for columns, and the values larger than 4 are observed for beams. However, for some cases of columns, $R_{\mu \mathrm{L} \phi}$ can be significant even if plastic hinges are not developed. For example, for columns of Story $3(\mathrm{ST}=3)$, NS direction and $S_{\mathrm{a}}=0.6 \mathrm{~g}, R_{\mu \mathrm{L} \phi}$ equals 1.95 ; this is an interesting point since, although yielding did not occur on these columns (i.e. $\mu_{\mathrm{L} \phi}=1.00$ ), bending moments are considerably reduced implying that yielding on beams reduce not only their bending moments but also those of columns. From the results of the 10-level building, it can be observed that the maximum values of $R_{\mu \mathrm{L} \phi}$ occur for the two stories below the roof (the values larger than 5 are observed for $S_{\mathrm{a}}=0.6 \mathrm{~g}$ ) and that these values are larger than those of the 3-level building.

4.2.2. Story Ductility Reduction Factor. The story ductility reduction factor $\left(R_{\mu \mathrm{S}}\right)$, calculated according to Equation (6), is now discussed. Even though, as for the case of story ductility demands, $R_{\mu \mathrm{S}}$ is calculated for several levels of structural deformation, the value of this parameter associated with a deformation state close to that of a collapse mechanism is that considered in the seismic guidelines [69]. The results are given in Table 4 and in Figures 4(c) and 4(d), for the 3- and 10-level models, respectively. For the 3-level building, no trend is observed between the mean values and the story number. For the case of the maximum deformation, the mean values are 3.10 and 3.06, for the NS and EW directions, respectively. As for the case of local and story ductility, the values are larger for $R_{\mu \mathrm{L} \phi}$ than for $R_{\mu \mathrm{S}}$ and, however, the differences are larger for the case of ductility demands. For the 10-level building, unlike the 3-story building, the mean values of $R_{\mu \mathrm{S}}$, even though not in a perfect way, tend to increase with the story number. The values seem to be larger for the 10-level building than that for the 3-level building, values larger than 4 are observed in some cases.

4.2.3. Global Ductility Reduction Factor. The mean values of global ductility reduction factors $\left(\mathrm{R}_{\mu \mathrm{G}}\right)$ are presented in
Table 5 for all cases. The results indicate that, for maximum deformation, $R_{\mu \mathrm{G}}$ are quite similar for both structural models, and the values range from 2.87 to 3.09 . It is implicitly assumed in the seismic codes mentioned in Section 1 that the magnitude of the global ductility reduction factor is about 4 . According to the results found in this paper, this value is not justified; a value of 3 seems to be more reasonable.

4.2.4. Ratio of Ductility Reduction Factor to Ductility. The ratios of the ductility reduction factor to ductility, for local $\left(Q_{\mathrm{L}}\right)$, story $\left(Q_{\mathrm{S}}\right)$, and global $\left(Q_{\mathrm{G}}\right)$ structural levels, are presented in this section. They are expressed as

$$
\begin{array}{r}
\mathrm{Q}_{\mathrm{L}}=\frac{R_{\mu \mathrm{L} \phi}}{\mu_{\mathrm{L} \phi}}, \\
\mathrm{Q}_{\mathrm{S}}=\frac{R_{\mu \mathrm{S}}}{\mu_{\mathrm{S}}}, \\
\mathrm{Q}_{\mathrm{G}}=\frac{R_{\mu \mathrm{G}}}{\mu_{\mathrm{G}}} .
\end{array}
$$

The values of $Q_{\mathrm{L}}$ are given in last rows of Table 3 and in Figure 5, for the 3- and 10-level buildings, respectively. The results indicate that this ratio significantly varies with the type of the structural element (beam or column), story number, strong motion intensity, and building height. For beams of the two models, the $Q_{\mathrm{L}}$ values tend to decrease with the strong motion intensity, but they tend to increase with the story number for the 3-level building. For the case or maximum deformation, $Q_{\mathrm{L}}$ is quite similar for the two models; the values range from 0.32 to 0.6 . Most of the observations made for beams apply to the case of columns, and however, an important difference is that the $Q_{\mathrm{L}}$ values are significantly larger for columns; the values of up to 2.4 and 3.0 are observed for the 3- and 10-level buildings, respectively. This result has an important implication: while the well-known ratio between ductility reduction factor to ductility $[10,33]$ indicates that, for the structural models under consideration (fundamental lateral vibration periods of 1.03 and 2.41), the maximum reduction in the elastic forces should be equal to ductility capacity, and the results in this paper show that the reduction for local response parameters like bending moment in columns can be much larger than that. The implication of this is that the design of columns will be too conservative if the reduction is performed according to the mentioned well-known ratio.

The results for $Q_{\mathrm{S}}$ are presented in the last rows of Table 4 and in Figure 6, for the 3- and 10-level buildings, respectively, while those of $Q_{\mathrm{G}}$ are given in the last row of Table 5. The $Q_{\mathrm{S}}$ values resemble those of $Q_{\mathrm{L}}$ in the sense that they decrease with the strong motion intensity and that they are quite similar for the two buildings. However, they can be significantly larger for the case of beams; for the maximum deformation, they range from 0.68 to 0.86 and from 0.60 to 1.10 for the 3- and the 10-level buildings, respectively. Regarding the $Q_{\mathrm{G}}$ parameter, the results in Table 5 indicate that, as for the local and story ratios, $Q_{\mathrm{G}}$ decreases with the 

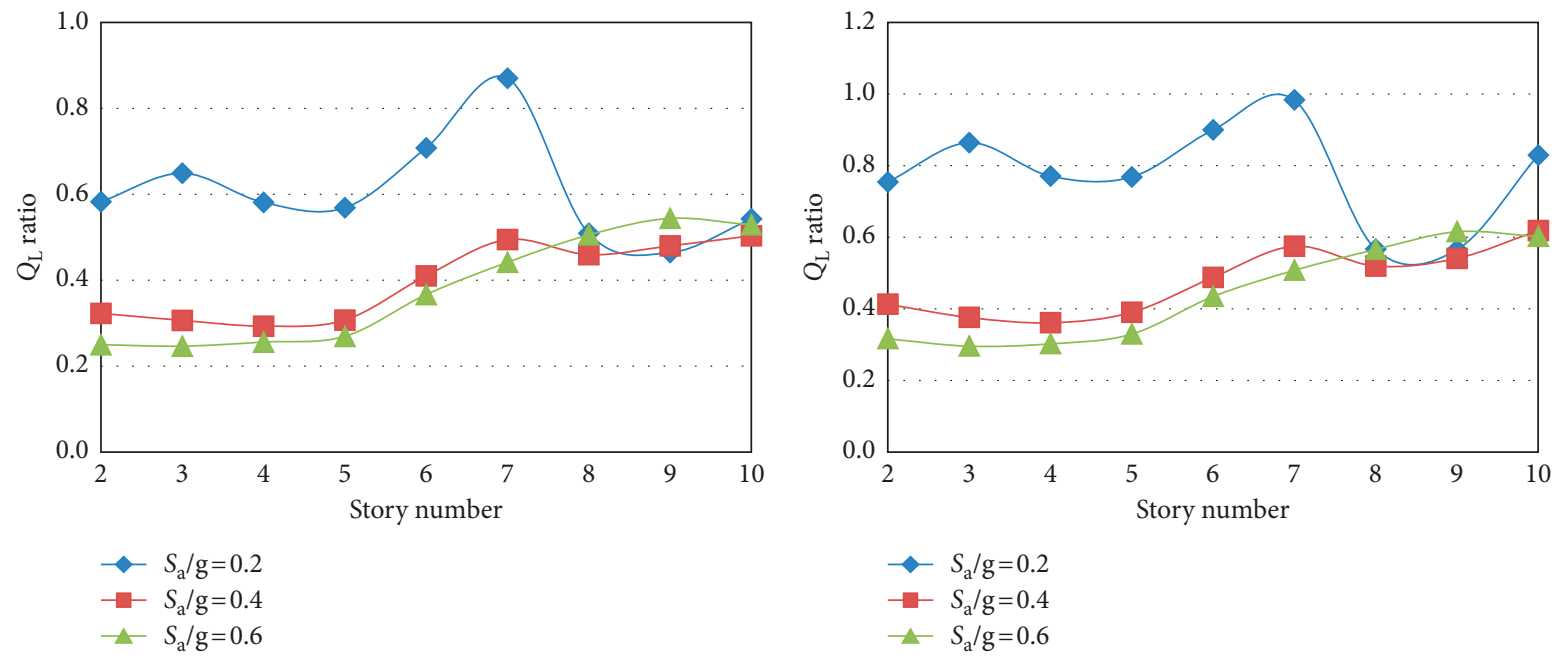

(a)

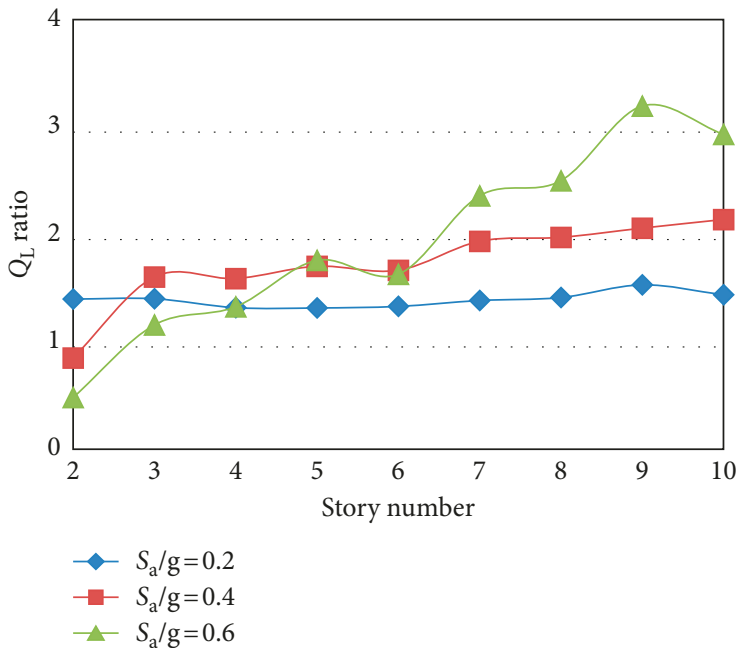

(c)

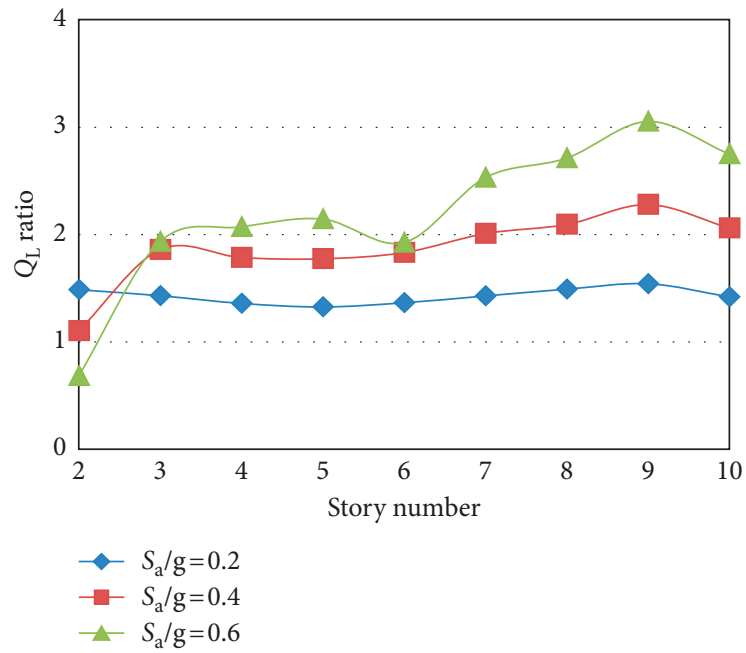

(d)

FigURE 5: $Q_{\mathrm{L}}$ ratio, 10-level building: (a) beams NS; (b) beams EW; (c) columns NS; (d) columns EW.

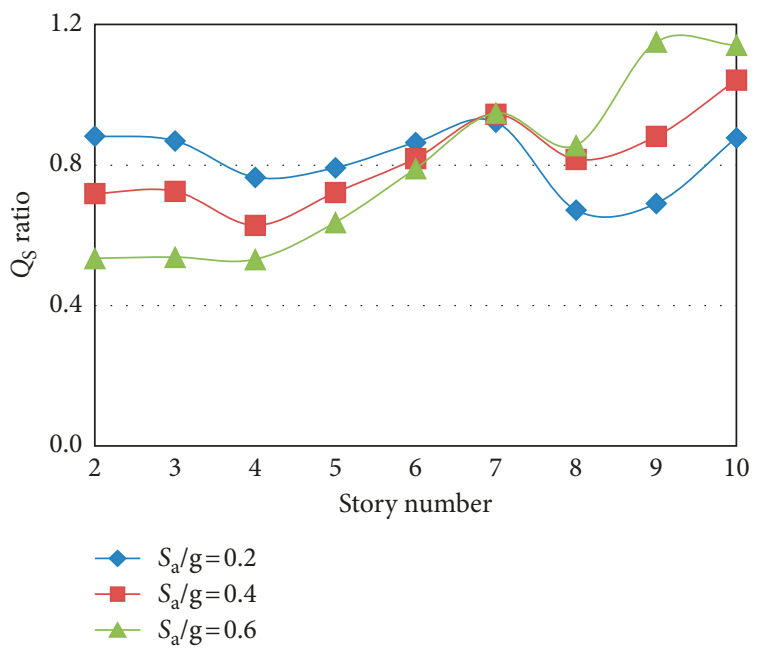

(a)

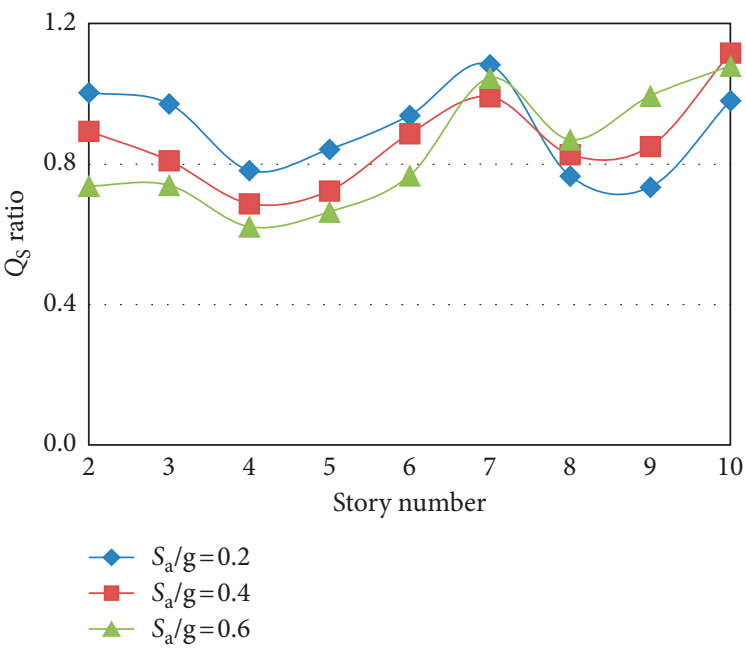

(b)

FIGURE 6: 10-level building, $Q_{S}$ ratio: (a) NS direction; (b) EW direction. 
intensity of the earthquakes; for the level of deformation associated with ductility capacity $\left(S_{\mathrm{a}}=1.2 \mathrm{~g}\right.$ and $\left.0.6 \mathrm{~g}\right)$, it takes values of $0.73,0.76,0.72$, and 0.86 . Thus, from an overall point of view, the ratio of the global ductility reduction factor to global ductility is about $3 / 4$, and it is the value proposed in this study. This value is smaller than the value of 1.00 specified by the well-known ratio $[10,33]$ abovementioned. The implication of this is that if the value of 1.00 is used to calculate the global ductility reduction factor, from a global point of view, nonconservative designs may result.

\subsection{Objective 3: Dissipated Energy}

4.3.1. Local, Story, and Global Normalized Dissipated Energy per Joint. As for the ductility demand and ductility reduction factor parameters, the dissipated energy is calculated for three levels. The mean values of $\left(E_{\mathrm{L} \phi}\right)_{\mathrm{SB}},\left(E_{\mathrm{L} \phi}^{*}\right)_{\mathrm{SC}}$, $E_{\mathrm{S}}$, and $E_{\mathrm{G}}$ are calculated according to Equations (10), (13)-(15), respectively. Plots for individual strong motions were developed for each beam, column, story, and the whole structure; however, only the results in terms of the mean values, averaged over all the strong motions, are given below. For the case of the 3-level building, the mean values of $\left(E_{\mathrm{L} \phi}\right)_{\mathrm{SB}}$ and $\left(E_{\mathrm{L} \phi}^{*}\right)_{\mathrm{SC}}$ are given in Table 6 , while those of $E_{\mathrm{S}}$ and $E_{\mathrm{G}}$ are given in Tables 7 and 8 , respectively. The corresponding results for the 10-level building are given in Figures 7 and 8 and in Table 8. In Table 8 , the symbols " $B+C$ " or " $B$ " indicate that $E_{\mathrm{G}}$ was calculated considering beam and columns, or only beams, respectively.

Results for the 3-level building indicate that $\left(E_{\mathrm{L} \phi}\right)_{\mathrm{SB}}$, $\left(E_{\mathrm{L} \phi}^{*}\right)_{\mathrm{SC}}$, and $E_{\mathrm{S}}$ tend to decrease with height and that $\left(E_{\mathrm{L} \phi}\right)_{\mathrm{SB}}$ is much larger than $\left(E_{\mathrm{L} \phi}^{*}\right)_{\mathrm{SC}}$, as expected. For the 10 -level building, $\left(E_{\mathrm{L} \phi}\right)_{\mathrm{SB}}$ and $\left(E_{\mathrm{L} \phi}^{*}\right)_{\mathrm{SC}}$ tend to increase and decrease with the story number, respectively; however, $E_{S}$ does not show a clear tendency. From a global point of view (Table 8), it is shown that the values of the global normalized dissipated energy $\left(E_{\mathrm{G}}\right)$, even for the maximum deformation, are relatively small when beams and columns are considered; the maximum observed values are 0.129 and 0.218 for the 3 - and 10-level buildings, respectively. These relatively small values of $E_{\mathrm{G}}$ are due to the fact that the normalized energy demands in columns are quite small so the average values obtained from Equations (14) and (15) for the whole frame are expected to be small too. The $E_{\mathrm{G}}$ parameter is also calculated by assuming that the plasticization of the steel frames, perfectly follows the strong column-weak beam concept; in other words, the dissipation of energy in columns is not considered. It is observed from Table 8 in this case that the maximum values of $E_{\mathrm{G}}$ are now 0.324 and 0.475 , for the 3 - and 10 -level models, respectively.

4.3.2. Ratio of Ductility Reduction Factor to Normalized Dissipated Energy. It is clear that the reduction of the response from the elastic to the inelastic case due to yielding of the material, which is quantified by the ductility reduction factor, is produced by the dissipated energy. In this regard, it may be of interest to study the ratio of the ductility reduction factor to dissipated energy. In this section of the paper, the ratio of the story ductility reduction factor to story normalized dissipated energy $\left(P_{\mathrm{S}}\right)$ and the ratio of global ductility reduction factor to global normalized dissipated energy $\left(P_{\mathrm{G}}\right)$ are given and discussed. They are calculated as

$$
\begin{gathered}
P_{\mathrm{S}}=\frac{R_{\mu \mathrm{S}}}{E_{\mathrm{S}}}, \\
P_{\mathrm{G}}=\frac{R_{\mu \mathrm{G}}}{E_{\mathrm{G}}} .
\end{gathered}
$$

The results for $P_{\mathrm{S}}$ are given in Table 9 and in Figure 9, for the 3- and 10-level models, respectively. The results for $P_{\mathrm{G}}$ are given in Table 8 for both models. In the calculation of $E_{S}$, only the dissipated energy at beams is considered. A value of $P_{\mathrm{S}}=R_{\mu \mathrm{S}}$, or $P_{\mathrm{G}}=R_{\mu \mathrm{G}}$, would mean that $E_{\mathrm{S}}=1.0$, or $E_{\mathrm{G}}=1.0$, which in turn would correspond to the idealized hypothetical case where all structural elements simultaneously reach, for every strong motion, the energy capacity. In other words, the energy demand equals the energy capacity in all cases. Obviously, it is not the case and, as shown below, values much larger than $R_{\mu \mathrm{S}}$ or $R_{\mu \mathrm{G}}$ are obtained for $P_{\mathrm{S}}$ or $P_{\mathrm{G}}$, respectively.

It is observed from Table 9 and Figure 9 that the $P_{\mathrm{S}}$ values significantly vary with the model height, the story number, and the strong motion intensity. Since energy dissipation produces the response reduction, one could expect a similar variation of $R_{\mu \mathrm{S}}$ and $E_{\mathrm{S}}$ which would approximately imply a constant value for $P_{S}$; however, these two parameters vary in a different proportion. The results clearly indicate that $P_{\mathrm{S}}$ tends to significantly increase with the story number for the 3-level building; this trend is not observed for the 10-level building. For both buildings, the $P_{\mathrm{S}}$ values significantly decrease with the strong motion intensity in most of the cases. One reason for this is that, as stated before, the seismic response significantly varies from one ground motion to another even though the level of deformation, in terms of $S_{\mathrm{a}}$, is approximately the same for any of the strong motions. This variation is observed even for two strong motions with a similar predominant period. These differences are due, in part, to the inherent variability existing in ground motions characterized by their frequency contents; it causes that the response be very sensitive to the particular characteristics of a given story or of a given building model and to the ground motion under consideration. This sensitivity is quite different from one response parameter to another and seems to be much larger for dissipation of energy than for the ductility reduction factor.

Results in Table 8 indicate that some of the observations made before for $P_{\mathrm{S}}$ apply the $P_{\mathrm{G}}$ Ratio. Based on the results associated with the maximum structural deformation, a value of 8 is proposed for this ratio. Thus, if the global normalized dissipated energy is estimated for a steel building with the structural system under consideration, the global ductility reduction factor can be estimated as eight times $E_{\mathrm{G}}$. 
TABLE 6: Mean values of $\left(E_{\mathrm{L} \phi}\right)_{\mathrm{SB}}$ and $\left(E_{\mathrm{L} \phi}^{*}\right)_{\mathrm{SC}}$, 3-level building.

\begin{tabular}{|c|c|c|c|c|c|c|c|c|c|c|c|}
\hline \multirow{3}{*}{ Type of member } & \multirow{3}{*}{ ST } & \multirow{2}{*}{\multicolumn{5}{|c|}{$\begin{array}{l}\text { NS direction } \\
S_{\mathrm{a}} / \mathrm{g} \text { values }\end{array}$}} & \multirow{2}{*}{\multicolumn{5}{|c|}{$\begin{array}{l}\text { EW direction } \\
S_{\mathrm{a}} / \mathrm{g} \text { values }\end{array}$}} \\
\hline & & & & & & & & & & & \\
\hline & & 0.4 & 0.6 & 0.8 & 1.0 & 1.2 & 0.4 & 0.6 & 0.8 & 1.0 & 1.2 \\
\hline \multirow{3}{*}{ Beams $\left(E_{\mathrm{L} \phi}\right)_{\mathrm{SB}}$} & 1 & 0.053 & 0.147 & 0.256 & 0.379 & 0.512 & 0.045 & 0.114 & 0.188 & 0.274 & 0.376 \\
\hline & 2 & 0.022 & 0.072 & 0.140 & 0.216 & 0.298 & 0.018 & 0.055 & 0.109 & 0.170 & 0.242 \\
\hline & 3 & 0.008 & 0.033 & 0.069 & 0.113 & 0.161 & 0.007 & 0.025 & 0.057 & 0.096 & 0.141 \\
\hline \multirow{3}{*}{ Columns $\left(E_{\mathrm{L} \phi}^{*}\right)_{\mathrm{SC}}$} & 1 & 0.003 & 0.010 & 0.025 & 0.046 & 0.076 & 0.003 & 0.007 & 0.017 & 0.031 & 0.050 \\
\hline & 2 & 0.001 & 0.003 & 0.004 & 0.007 & 0.013 & 0.001 & 0.003 & 0.004 & 0.006 & 0.010 \\
\hline & 3 & 0.001 & 0.001 & 0.002 & 0.004 & 0.007 & 0.001 & 0.001 & 0.002 & 0.004 & 0.007 \\
\hline
\end{tabular}

TABle 7: Mean values of $E_{S}$, 3-level building.

\begin{tabular}{|c|c|c|c|c|c|c|c|c|c|c|}
\hline \multirow{3}{*}{ ST } & \multicolumn{5}{|c|}{ NS direction } & \multicolumn{5}{|c|}{ EW direction } \\
\hline & \multicolumn{5}{|c|}{$S_{\mathrm{a}} / \mathrm{g}$ values } & \multicolumn{5}{|c|}{$S_{\mathrm{a}} / \mathrm{g}$ values } \\
\hline & 0.4 & 0.6 & 0.8 & 1.0 & 1.2 & 0.4 & 0.6 & 0.8 & 1.0 & 1.2 \\
\hline 1 & 0.020 & 0.056 & 0.102 & 0.157 & 0.221 & 0.017 & 0.043 & 0.074 & 0.112 & 0.158 \\
\hline 2 & 0.008 & 0.026 & 0.050 & 0.077 & 0.108 & 0.007 & 0.020 & 0.039 & 0.061 & 0.087 \\
\hline 3 & 0.003 & 0.012 & 0.024 & 0.040 & 0.058 & 0.003 & 0.009 & 0.020 & 0.035 & 0.052 \\
\hline
\end{tabular}

TABle 8: Mean values of $E_{\mathrm{G}}$ for the 3- and 10-level buildings.

\begin{tabular}{|c|c|c|c|c|c|c|c|c|c|c|c|c|c|c|c|c|c|}
\hline \multirow{3}{*}{ Parameter } & \multirow{3}{*}{ Member } & \multicolumn{10}{|c|}{ 3-level } & \multicolumn{6}{|c|}{ 10-level } \\
\hline & & \multicolumn{5}{|c|}{$\begin{array}{l}\text { NS direction } \\
S_{\mathrm{a}} / \mathrm{g} \text { values }\end{array}$} & \multicolumn{5}{|c|}{$\begin{array}{l}\text { EW direction } \\
S_{\mathrm{a}} / \mathrm{g} \text { values }\end{array}$} & \multicolumn{3}{|c|}{$\begin{array}{l}\text { NS direction } \\
S_{\mathrm{a}} / \mathrm{g} \text { values }\end{array}$} & \multicolumn{3}{|c|}{$\begin{array}{c}\text { EW direction } \\
S_{\mathrm{a}} / \mathrm{g} \text { values }\end{array}$} \\
\hline & & 0.4 & 0.6 & 0.8 & 1.0 & 1.2 & 0.4 & 0.6 & 0.8 & 1.0 & 1.2 & 0.2 & 0.4 & 0.6 & 0.2 & 0.4 & 0.6 \\
\hline \multirow[b]{2}{*}{$E_{\mathrm{G}}$} & $B+C$ & 0.011 & 0.031 & 0.059 & 0.091 & 0.129 & 0.009 & 0.024 & 0.044 & 0.069 & 0.099 & 0.026 & 0.111 & 0.218 & 0.017 & 0.083 & 0.171 \\
\hline & B & 0.028 & 0.084 & 0.155 & 0.236 & 0.324 & 0.023 & 0.065 & 0.118 & 0.18 & 0.253 & 0.076 & 0.314 & 0.383 & 0.047 & 0.241 & 0.475 \\
\hline$P_{\mathrm{G}}$ & & 48.2 & 21.1 & 13.9 & 10.7 & 8.9 & 63.0 & 28.8 & 19.3 & 14.7 & 11.7 & 19.3 & 7.3 & 7.8 & 31.7 & 9.7 & 6.5 \\
\hline
\end{tabular}

\section{Conclusions}

The ductility parameter plays a central role in seismic analysis and design of steel buildings. However, it is still used in an indirect way. A numerical investigation regarding the evaluation of local $\left(\mu_{\mathrm{L} \phi}\right)$, story $\left(\mu_{\mathrm{S}}\right)$, and global $\left(\mu_{\mathrm{G}}\right)$ ductility, local $\left(R_{\mu \mathrm{L} \phi}\right)$, story $\left(R_{\mu \mathrm{S}}\right)$, and global $\left(R_{\mu \mathrm{G}}\right)$ ductility reduction factors, as well as local $\left(E_{\mathrm{L} \phi}\right)$, story $\left(E_{\mathrm{S}}\right)$, and global $\left(E_{\mathrm{G}}\right)$ normalized dissipated energy, for steel buildings with moment-resisting frames, which were designed following the strong column-weak beam concept, is presented in this paper. The ratios of $\mu_{\mathrm{G}}$ to $\mu_{\mathrm{L} \phi}(\mathrm{Q}), R_{\mu \mathrm{L} \phi}$ to $\mu_{\mathrm{L} \phi}\left(Q_{\mathrm{L}}\right), R_{\mu \mathrm{S}}$ to $\mu_{\mathrm{S}}\left(Q_{\mathrm{S}}\right), R_{\mu \mathrm{G}}$ to $\mu_{\mathrm{G}}\left(Q_{\mathrm{G}}\right), R_{\mu \mathrm{S}}$ to $E_{\mathrm{S}}\left(P_{\mathrm{S}}\right)$, and $R_{\mu \mathrm{G}}$ to $E_{\mathrm{G}}\left(P_{\mathrm{G}}\right)$ are also calculated. 3- and 10-level buildings and some strong motions used in the SAC Steel Project are used in the study. The mentioned parameters are calculated for several intensities of the strong motions. Results of the study indicate that any of the abovementioned parameters significantly may vary with the strong motion, the seismic intensity, the structural element, the story number, and the structural model. The main findings are as follows:

(1) Bending local ductility capacity $\left(\mu_{\mathrm{L} \phi}\right)$ of beams can reach values of up to 20 for some individual strong motions, as observed in some experimental investigations. On an average basis, $\mu_{\mathrm{L} \phi}$ ranges from
7 to 14 . The values are larger for the 10-level building than for the 3-level building, reflecting the effect of the structural complexity on the $\mu_{\mathrm{L} \phi}$ parameter. Many of the observations made for $\mu_{\mathrm{L} \phi}$ apply to $\mu_{\mathrm{S}}$, but the values are much smaller than those of $\mu_{\mathrm{L} \phi}$; they range from 3 to 5 . The corresponding values of $\mu_{\mathrm{G}}$ range from 3.6 to 3.95 . A value of $1 / 3$ is proposed for the $Q$ ratio. Thus, if local ductility capacity is stated as the basis for the design, global ductility capacity can be calculated by using this ratio.

(2) The mean values of $R_{\mu \mathrm{L} \phi}$ for beams range between 3.5 and 5, which are larger than those of columns. Even though yielding did not occur in columns for many cases, a considerable reduction is observed in bending moments implying that yielding on beams reduce not only their bending moments but also those of columns. The maximum mean values of $R_{\mu \mathrm{S}}$ is about 4.0. The $\mathrm{R}_{\mu \mathrm{G}}$ mean values range from 2.87 to 3.09. It is implicitly assumed in the seismic codes that the magnitude of the global ductility reduction factor is about 4. According to the results found in this paper, this value is not justified; a value of 3 seems to be more reasonable and is proposed in this study.

(3) The maximum values of $Q_{\mathrm{L}}$ range from 0.32 to 0.6 for beams; for columns, however, they are significantly 


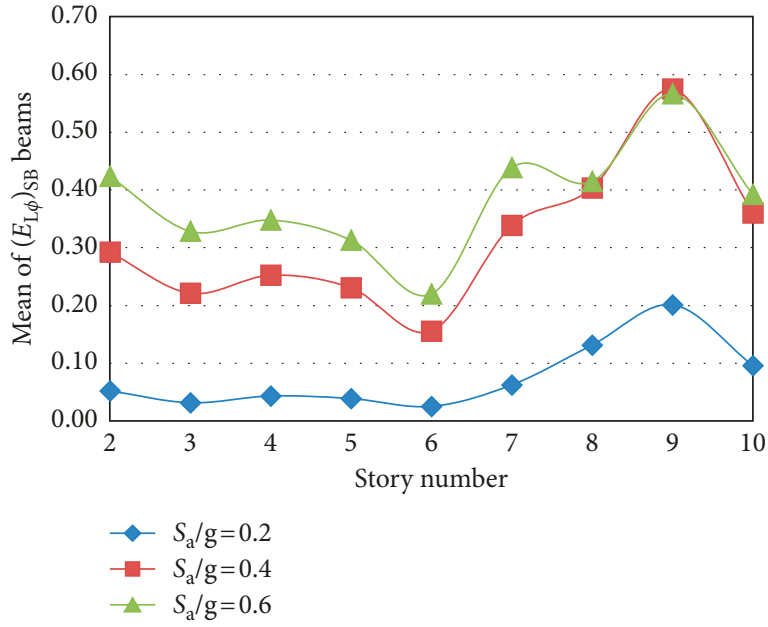

(a)

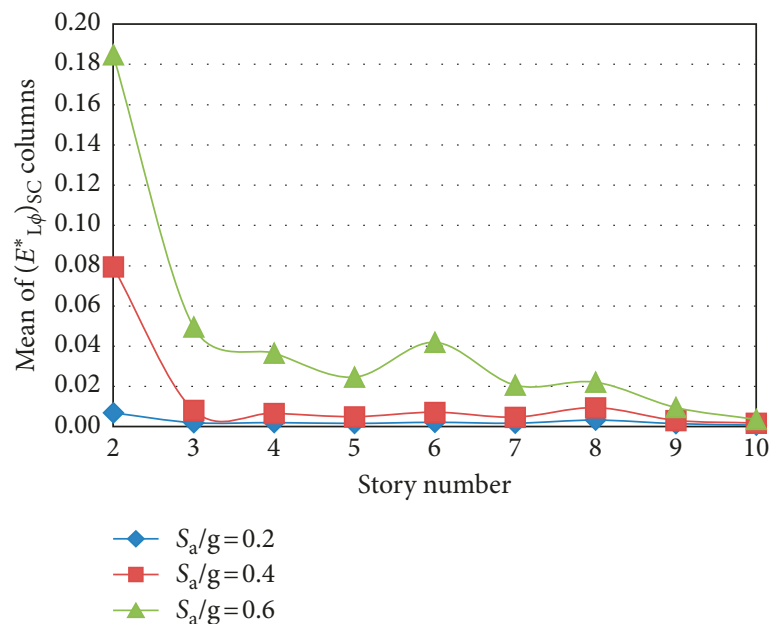

(c)

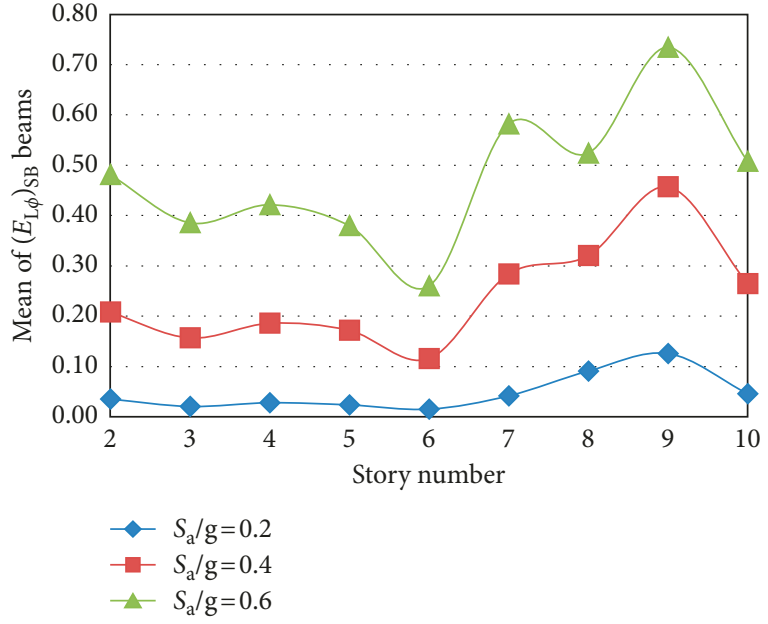

(b)

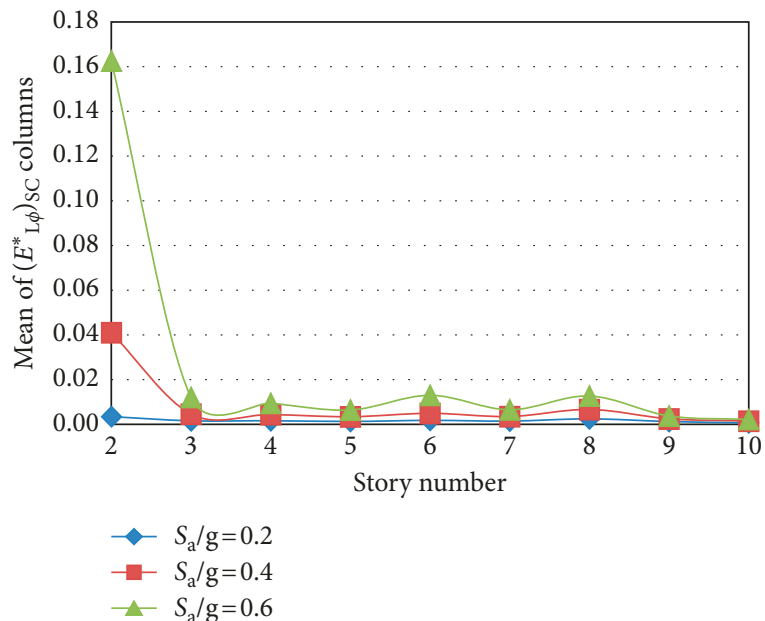

(d)

Figure 7: Mean values of local normalized energy demands, 10-level building: (a) beams NS; (b) beams EW; (c) columns NS; (d) columns EW.

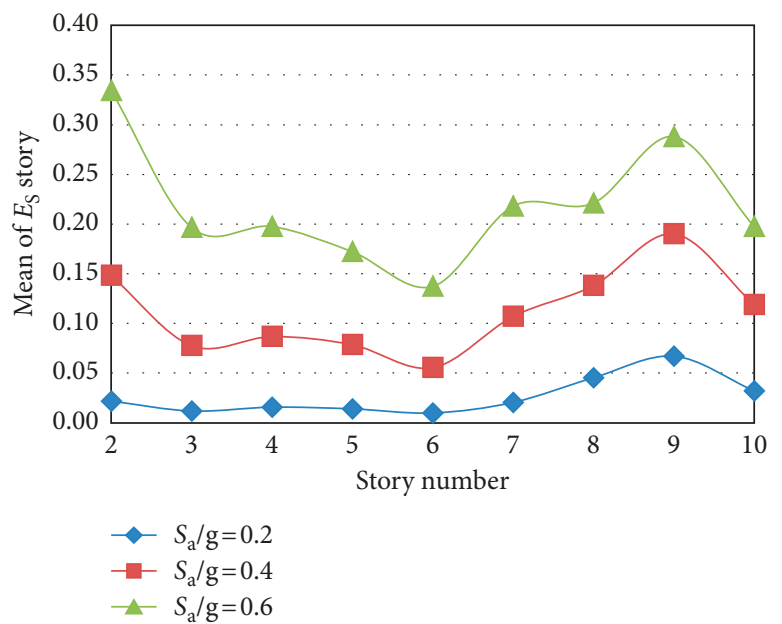

(a)

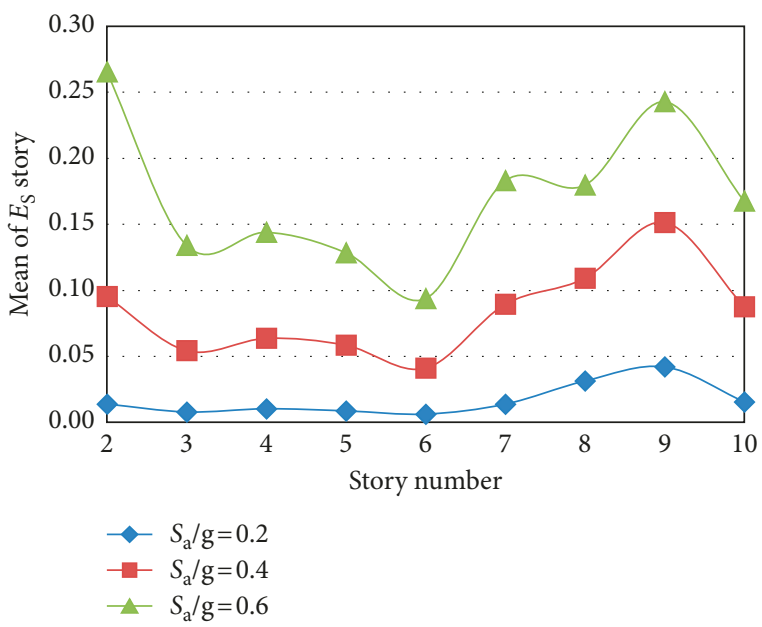

(b)

Figure 8: Mean values of story normalized energy demands, 10-level building: (a) NS direction; (b) EW direction. 
TABLe 9: $P_{\mathrm{S}}$ ratio, 3-level building.

\begin{tabular}{|c|c|c|c|c|c|c|c|c|c|c|}
\hline \multirow{3}{*}{ ST } & \multirow{2}{*}{\multicolumn{5}{|c|}{$\begin{array}{l}\text { NS direction } \\
S_{\mathrm{a}} / \mathrm{g} \text { values }\end{array}$}} & \multirow{2}{*}{\multicolumn{5}{|c|}{$\begin{array}{c}\text { EW direction } \\
S_{\mathrm{a}} / \mathrm{g} \text { values }\end{array}$}} \\
\hline & & & & & & & & & & \\
\hline & 0.4 & 0.6 & 0.8 & 1.0 & 1.2 & 0.4 & 0.6 & 0.8 & 1.0 & 1.2 \\
\hline 1 & 27.5 & 12.9 & 9.3 & 7.3 & 6.1 & 29.6 & 15.2 & 11.2 & 9.2 & 7.7 \\
\hline 2 & 65.5 & 25.8 & 16.4 & 12.4 & 10.2 & 75.6 & 33.5 & 20.6 & 15.8 & 12.6 \\
\hline 3 & 181.3 & 55.8 & 31.4 & 21.9 & 17.1 & 194.3 & 70.0 & 36.5 & 24.6 & 18.9 \\
\hline
\end{tabular}

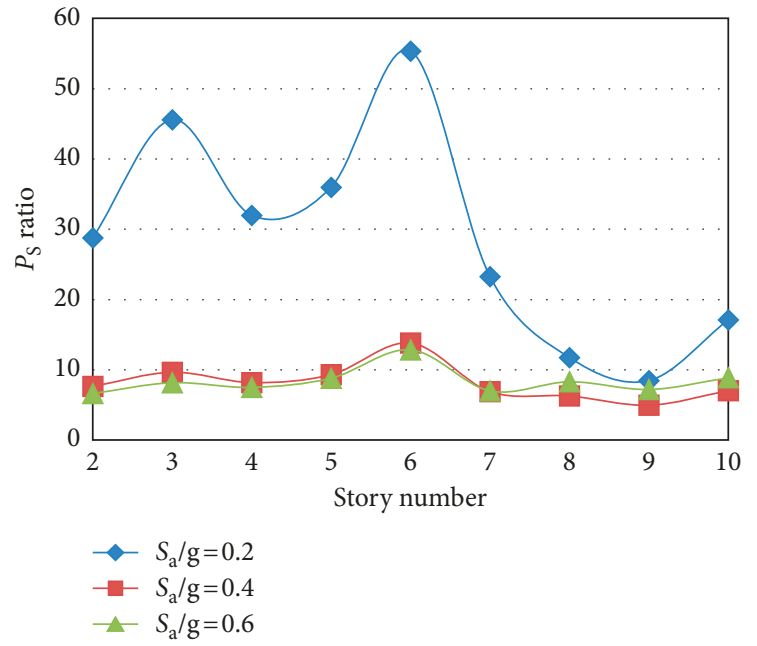

(a)

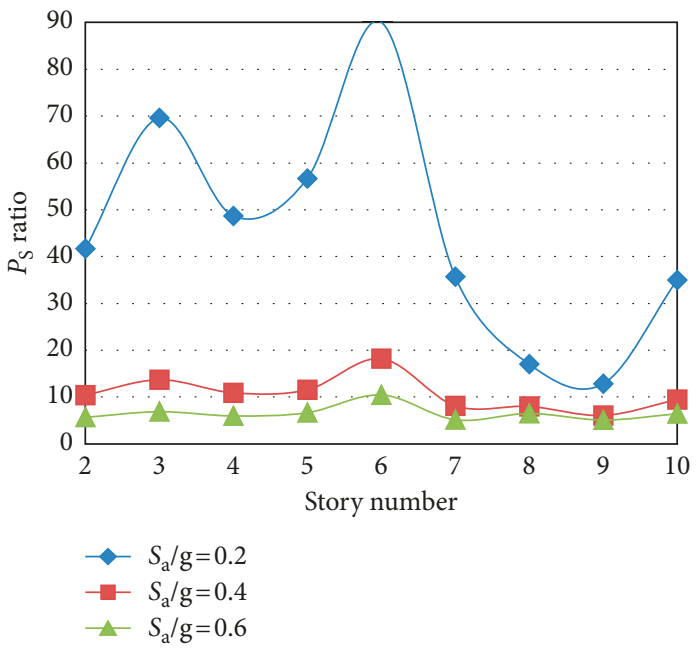

(b)

FIGURE 9: $P_{\mathrm{S}}$ ratio, 10-level building: (a) NS direction; (b) EW direction.

larger; values larger than 2 are observed in many cases. The maximum values of $Q_{\mathrm{S}}$ range from 0.60 to 1.10 while those of $Q_{\mathrm{G}}$ from 0.73 to 0.86 . These values are smaller than the specified well-known ratio of 1.00. The implication of this is that if the value of 1.00 is used to calculate the global ductility reduction factor, from a global point of view nonconservative designs may result, while from a local point of view, as is the case of columns, very conservative designs may result. A value of $Q_{G}$ of $3 / 4$ is proposed in this study.

(4) The $E_{\mathrm{L} \phi}$ values for beams for maximum deformation range from 0.15 to 0.7 , which are much larger than those of columns and larger than those of $E_{\mathrm{S}}$. The maximum values of $E_{\mathrm{G}}$ range from 0.25 to 0.47 . The values of the $P_{\mathrm{S}}$ ratio significantly decrease with the strong motion intensity and significantly increase with the story number, in most of the cases. Based on the results associated with the maximum deformation, a value of 8 is proposed for the $P_{\mathrm{G}}$ ratio.

\section{Data Availability}

Data used to support the findings of this study are included within the article, and data supporting this study are from previously reported studies, which have been cited.

\section{Disclosure}

Any opinions, findings, conclusions, or recommendations expressed in this publication are those of the authors and do not necessarily reflect the views of the sponsors.

\section{Conflicts of Interest}

The authors declare that there are no conflicts of interest regarding the publication of this paper.

\section{Acknowledgments}

The research presented in this paper was financially supported by La Universidad Autónoma de Sinaloa (UAS) under grant PROFAPI-2015/235.

\section{References}

[1] International Code Council, International Building Code, International Code Council, Falls Church, VA, USA, 2009.

[2] NBCC, Canadian Commission on Building and Fire Codes, The National Building Code of Canada, National Research Council, Ottawa, Canada, 2010.

[3] MFDC, Government of the Federal District, Complementary Technical Norms for Seismic Design, Official Gazette of the Federal District, Mexico, 2004.

[4] EC, Committee European de Normalization, European Standard, Eurocode 8, Design of Structures for Earthquake Resistance, CEN, Brussels, Belgium, 2004. 
[5] C. M. Uang, "Establishing R (or Rw) and Cd factors for building seismic provisions," Journal of Structural Engineering ASCE, vol. 117, no. 1, pp. 19-28, 1991.

[6] C. M. Uang, "Structural overstrength and limit state philosophy in seismic design provisions," Report No CE-91-03, Department of Civil Engineering, Northeastern University, 1991.

[7] SAC, "Steel moment frame connections," Advisory No. 3, D-146. Structural Engineers Associated of California, Applied Technology Council and California University for Research in Earthquake Engineering, Sacramento, CA, USA, 1995.

[8] A. Reyes-Salazar, "Ductility and ductility reduction factors," Structural Engineering and Mechanics An International Journal, vol. 13, no. 4, pp. 369-385, 2002.

[9] Applied Technology Council, "Tentative provisions for the development of seismic regulation buildings," Rep. No. ATC3-06, Applied Technology Council, Redwood City, CA, USA, 1978.

[10] N. M. Newmark and W. J. Hall, Earthquake Spectra and Design Monograph Series, Earthquake Engineering Research Institute, Berkeley, CA, USA, 1982.

[11] A. H. Hadjian, "An evaluation of the ductility reduction factor Q in the 1976 regulations for the federal district of Mexico," Earthquake Engineering and Structural Dynamics, vol. 18, pp. 217-231, 1989.

[12] E. Miranda and V. Bertero, "Evaluation of strength reduction factors for earthquake-resistant design," Earthquake Spectra, vol. 10, no. 2, pp. 357-379, 1994.

[13] A. Whittaker, G. Hart, and C. Rojahn, "Seismic response modification factors," Journal of Structural Engineering, vol. 125, no. 4, pp. 438-444, 1999.

[14] D. Arroyo-Espinoza and A. Teran-Gilmore, "Strength reduction factors for ductile structures with passive energy dissipating devices," Journal of Earthquake Engineering, vol. 7, no. 2, pp. 297-325, 2003.

[15] R. Levy, A. Rutenberg, and K. H. Qadi, "Equivalent linearization applied to earthquake excitations and the R- $\mu$-T0 relationships," Engineering Structures, vol. 28, no. 2, pp. 216-228, 2006.

[16] D. Karmakar and V. K. Gupta, "A parametric study of strength reduction factors for elasto-plastic oscillators," Sädhanā, vol. 31, no. 4, pp. 343-357, 2006.

[17] R. Rupakhety and R. Sigbjörnsson, "Ground-motion prediction equations (GMPEs) for inelastic response and structural behavior factors," Bulletin of Earthquake Engineering, vol. 7, no. 3, pp. 637-659, 2009.

[18] L. Sanchez-Ricart, "Assessment and management of risk for engineered systems and geohazards," Georisk, vol. 4, no. 4, pp. 208-229, 2010.

[19] A. M. Halabian and S. Kabiri, "Effect of foundation flexibility on ductility reduction factors or R/C stack-like structures," Earthquake Engineering and Engineering Vibration, vol. 10, no. 2, pp. 277-329, 2011.

[20] M. AlHamaydeh, S. Abdullah, A. Hamid, and A. Mustapha, "Seismic design factors for RC special moment resisting frames in Dubai, UAE," Earthquake Engineering \& Engineering Vibration, vol. 10, no. 4, pp. 495-506, 2011.

[21] S. Naimi, M. Celikag, and A. A. Hedayat, "Ductility enhancement of post-Northridge connections by multilongitudinal voids in the beam web," Scientific World Journal, vol. 2013, Article ID 515936, 14 pages, 2013.

[22] M. Azimi, A. B. Adnan, A. R. B. M. Sam et al., "Seismic performance of RC beam-column connections with continuous rectangular spiral transverse reinforcements for low ductility classes," Scientific World Journal, vol. 2014, Article ID 802605, 12 pages, 2014.

[23] N. Fanaie and S. O. Shamlou, "Response modification factor of mixed structures," Steel and Composite Structures, vol. 19, no. 6, pp. 1449-1466, 2015.

[24] C. H. Zhai, W. P. Wen, S. Li, and L. L. Xie, "The ductilitybased strength reduction factor for the mainshock-aftershock sequence-type ground motions," Bulletin of Earthquake Engineering, vol. 13, no. 10, pp. 2893-2914, 2015.

[25] C. Wang, Y. Shen, R. Yang, and Z. Wen, "Ductility and ultimate capacity of prestressed steel reinforced concrete beams," Mathematical Problems in Engineering, vol. 2017, Article ID 1467940, 6 pages, 2017.

[26] H. C. Cho, M. K. Park, H. Ju et al., "Shear strength reduction factor of prestressed hollow-core slab units based on the reliability approach," Advances in Materials Science and Engineering, vol. 2017, Article ID 8280317, 11 pages, 2017.

[27] A. Nassar and H. Krawinkler, "Seismic demands of SDOF and MDOF systems," Report No. 95, John A. Blume Earthquake Engineering Center, Stanford University, Stanford, CA, USA, 1991.

[28] H. Moghaddam and R. K. Mohammadi, "Ductility reduction factor of MDOF shear-building structures," Journal of Earthquake Engineering, vol. 5, no. 1, pp. 425-440, 2001.

[29] A. S. Elnashai and A. M. Mwafy, "Overstrength and force reduction factors of multistorey reinforced-concrete buildings," Structural Design of Tall and Special Buildings, vol. 11, no. 5, pp. 329-351, 2002.

[30] R. Medina and H. Krawinkler, "Strength demand issues relevant for the seismic design of moment-resisting frames," Earthquake Spectra, vol. 21, no. 2, pp. 415-439, 2005.

[31] M. De Stefano, E. M. Marino, and P. P. Rossi, "Effect of overstrength on the seismic behaviour of multi-storey regularly asymmetric buildings," Bulletin of Earthquake Engineering, vol. 4, no. 1, pp. 23-42, 2006.

[32] J. Cai, J. Zhou, and X. Fang, "Seismic ductility reduction factors for multi-degree-of-freedom systems," Advances in Structural Engineering, vol. 9, no. 5, pp. 591-601, 2006.

[33] A. K. Chopra, Dynamics of Structures, Prentice-Hall, Upper Saddle River, NJ, USA, 2007.

[34] F. Mollaioli and S. Bruno, "Influence of side effects on inelastic displacement ratios for SDOF and MDOF systems," Computers \& Mathematics with applications, vol. 55, no. 2, pp. 184-207, 2008.

[35] J. C. Vielma, A. H. Barbat, and S. Oller, "Seismic safety of low ductility structures used in Spain," Bulletin of Earthquake Engineering, vol. 8, no. 1, pp. 135-155, 2010.

[36] M. Ceylan, M. H. Arslan, R. Ceylan, M. Y. Kaltakci, and Y. Ozbay, "A new application area of ANN and ANFIS: determination of earthquake load reduction factor of prefabricated industrial buildings," Civil Engineering and Environmental Systems, vol. 27, no. 1, pp. 53-69, 2010.

[37] Q. Honglue, Z. Jianjing, and J. X. Zhao, "Strength reduction factors for seismic analyses of buildings exposed to near-fault ground motions," Earthquake Engineering and Engineering Vibration, vol. 10, no. 2, pp. 195-209, 2011.

[38] B. Ganjavi and H. Hao, "Effect of structural characteristics distribution of strength demand and ductility reduction factor of MDOF systems considering soil-structure interaction," Earthquake Engineering and Engineering Vibration, vol. 11, no. 2, pp. 205-220, 2012.

[39] M. H. Serror, R. A. Diab, and S. A. Mourad, "Seismic force reduction factor for steel moment resisting frames with 
supplemental viscous dampers," Earthquakes and Structures An International Journal, vol. 7, no. 6, pp. 1171-1186, 2014.

[40] E. Bojórquez, S. E. Ruiz, A. Reyes-Salazar, and J. Bojórquez, "Ductility and strength reduction factors for degrading structures considering cumulative damage," Scientific World Journal, vol. 2014, Article ID 575816, 7 pages, 2014.

[41] H. Chaulagain, H. Rodrigues, E. Spacone et al., "Response reduction factor of irregular RC buildings in Kathmandu valley," Earthquake Engineering \& Engineering Vibration, vol. 13, no. 3, pp. 455-470, 2014.

[42] A. Reyes-Salazar, E. Bojórquez, J. I. Velazquez-Dimas, A. López-Barraza, and J. L. Rivera-Salas, "Ductility and ductility reduction factors for steel buildings considering different structural representations," Bulletin of Earthquake Engineering, vol. 13, no. 6, pp. 1749-1771, 2015.

[43] E. Vuran and M. N. Aydınoğlu, "Capacity and ductility demand estimation procedures for preliminary design of coupled core wall systems of tall building," Bulletin of Earthquake Engineering, vol. 14, no. 3, pp. 721-745, 2016.

[44] F. Gómez-Martínez, A. Alonso-Durán, F. De Luca, and G. M. Verderame, "Ductility of wide-beam RC frames as lateral resisting system," Bulletin of Earthquake Engineering, vol. 14, no. 6, pp. 1545-1569, 2016.

[45] G. Liu, J. Lian, C. Liang, and M. Zhao, "Structural response analysis in time and frequency domain considering both ductility and strain rate effects under uniform and multiplesupport earthquake excitations," Earthquakes and Structures, vol. 10, no. 5, pp. 989-1012, 2016.

[46] S. S. Hashemi, K. Sadeghi, M. Vaghefi, and K. Shayan, "Evaluation of ductility and response modification factor in moment-resisting steel frames with CFT columns," Earthquakes and Structures, vol. 12, no. 6, pp. 643-652, 2017.

[47] A. Reyes-Salazar and A. Haldar, "Dissipation of energy in steel frames with PR Connections," Structural Engineering and Mechanics, vol. 9, no. 3, pp. 241-256, 2000.

[48] A. Reyes-Salazar and A. Haldar, "Energy dissipation at PR frames under seismic loading," Journal of Structural Engineering ASCE, vol. 127, no. 5, pp. 588-593, 2001.

[49] A. Reyes-Salazar and A. Haldar, "Seismic response and energy dissipation in partially restrained and fully restrained steel frames: an analytical study," Steel \& Composite Structures, vol. 1, no. 4, pp. 459-480, 2001.

[50] FEMA, Federal Emergency Management Agency, "State of the art report on systems performance of steel moment frames subjected to earthquake ground shaking, SAC steel project," Report 355C, FEMA, Federal Emergency Management Agency, Oakland, CA, USA, 2000.

[51] BOCA, National Building Code, Building Officials \& Code Administration International Inc., Country Club Hills, IL, USA, 12th edition, 1993.

[52] A. J. Carr, "RUAUMOKO", Inelastic Dynamic Analysis Program, Department of Civil Engineering, University of Canterbury, Christchurch, New Zealand, 2011.

[53] W. F. Chen and T. Atsuta, "Interaction equations for biaxially loaded sections," Fritz Laboratory Report (72-9), Paper 284, Lehigh University, Bethlehem, Pennsylvania, USA, 1971.

[54] C. W. Roeder, S. P. Scheiner, and J. E. Carpenter, "Seismic behavior of moment-resisting steel frames: analytical study," Journal of Structural Engineering, ASCE, vol. 119, no. 6, pp. 1866-1884, 1993.

[55] C. W. Roeder, S. P. Scheiner, and J. E. Carpenter, "Seismic behavior of moment-resisting steel frames: experimental study," Journal of Structural Engineering, ASCE, vol. 119, no. 6, pp. 1885-1902, 1993.
[56] R. T. Leon and K. J. Shin, "Performance of semi-rigid frames," in Proceedings of Structure Congress, pp. 1020-1035, Boston, Massachusetts, USA, 1995.

[57] M. N. Naderand and A. Astaneh, "Dynamic behavior of flexible, semirigid and rigid frames," Journal of Constructional Steel Research, vol. 18, no. 3, pp. 179-192, 1991.

[58] A. Osman, A. Ghobarah, and R. M. Korol, "Implications of design philosophies of seismic response of steel moments frame," Earthquake Engineering and Structural Dynamics, vol. 24, no. 1, pp. 127-143, 1995.

[59] J. D. Osteraas and H. Krawinkler, "Strength and ductility considerations in seismic design," Report No. 90, Blume Earthquake Engineering Center, Stanford University, 1990.

[60] B. Akbas, Energy-based earthquake resistant design of steel moment resisting frames, Ph.D. thesis, Department of Civil and Architectural Engineering, Illinois Institute of Technology, Chicago, IL, USA, 1997.

[61] B. Akbas, J. Shen, and H. Hao, "Energy approach in performance-based design of steel moment resisting frames for basic safety objective," Structural Design of Tall Buildings, vol. 10, no. 3, pp. 193-217, 2001.

[62] B. Calderoni and Z. Rinaldi, "Inelastic dynamic and static analysis for steel MRF seismic design," in Behaviour of Steel Structures in Seismic Areas STESSA 2000, Balkema, Rotterdam, Netherlands, 2000.

[63] B. Calderoni and Z. Rinaldi, "Seismic performance evaluation for steel MRF: nonlinear dynamic and static analyses," Steel and Composite Structures An International Journal, vol. 2, no. 2, pp. 113-128, 2002.

[64] M. Brescia, R. Landolfo, O. Mammana et al., "Preliminary results of an experimental program on the cyclic response and rotation capacity of steel members," in Behaviour of Steel Structures in Seismic Areas STESSA 2009, CRC Press, Philadelphia, PA, USA, 2009.

[65] E. Bojorquez, A. Reyes-Salazar, A. Terán-Gilmore, and S. E. Ruiz, "Energy-based damage index for steel structures," Steel and Composite Structures An International Journal, vol. 4, no. 10, pp. 331-348, 2010.

[66] T. V. Galambos, Structural Members and Frames, Prentice Hall, Englewood Cliffs, NJ, USA, 2016.

[67] A. Liew, L. Gardner, and P. Block, "Moment-curvature-thrust relationships for beam-columns," Structures, vol. 11, pp. 146-154, 2017.

[68] J. Zhou, F. He b, and T. Liu, "Curvature ductility of columns and structural displacement ductility in RC frame structures subjected to ground motions," Soil Dynamics and Earthquake Engineering, vol. 63, pp. 174-183, 2014.

[69] C. M. Uang and M. Bruneau, "State-of-the-art review on seismic design of steel structures," Journal of Structural Engineering, ASCE, vol. 144, no. 4, article 03118002, 2018. 


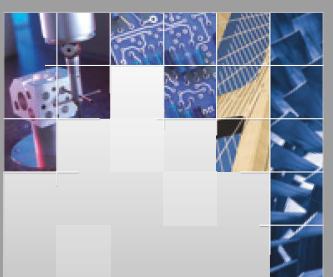

\section{Enfincering}
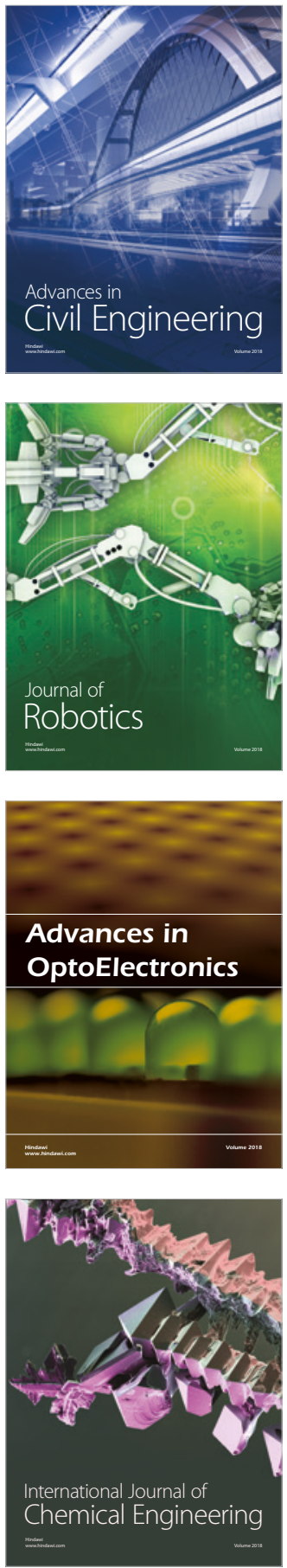

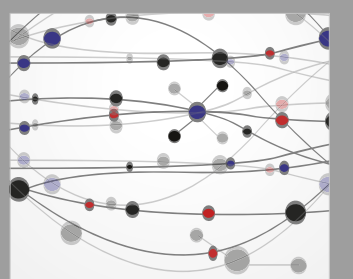

\section{Rotating \\ Machinery}

The Scientific World Journal

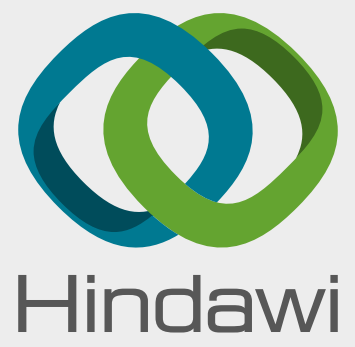

Submit your manuscripts at

www.hindawi.com
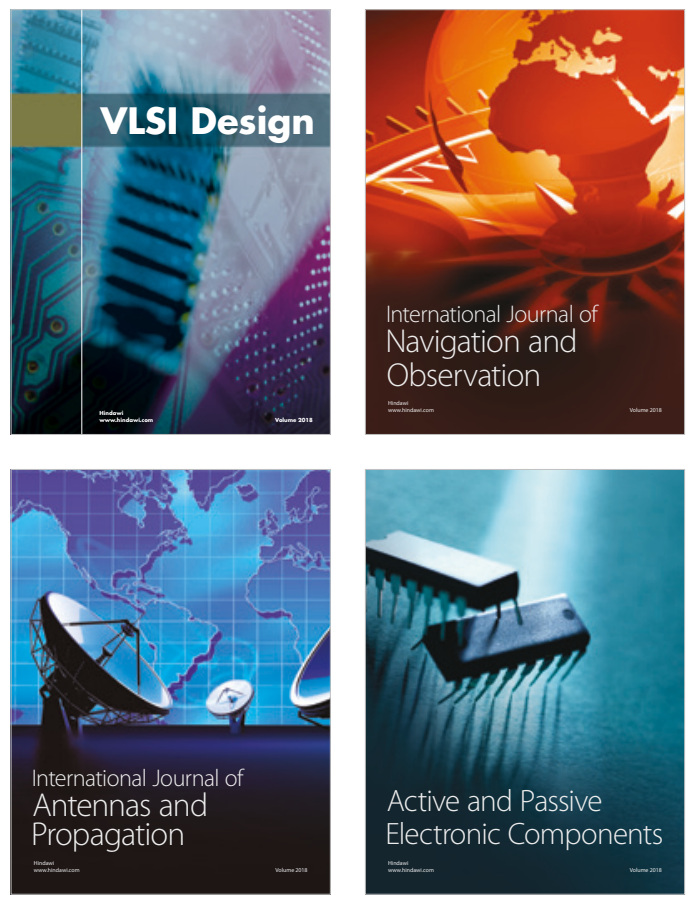
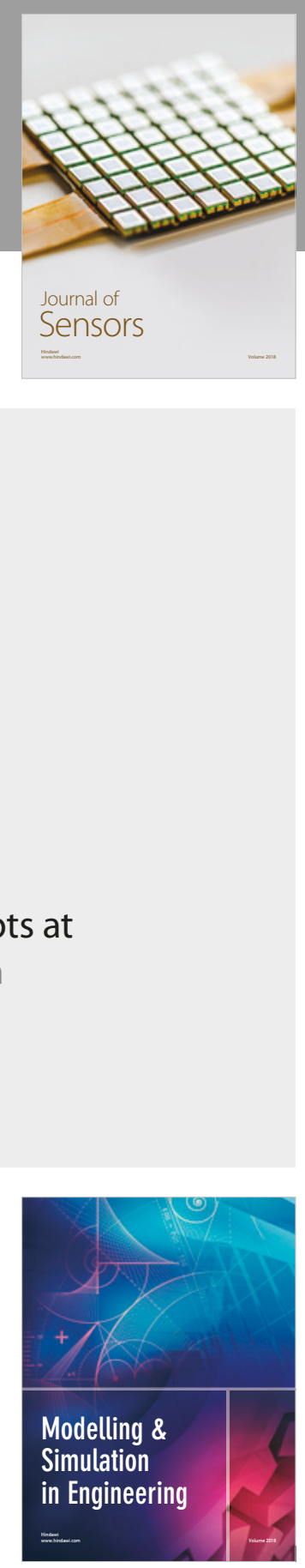

\section{Advances \\ Multimedia}
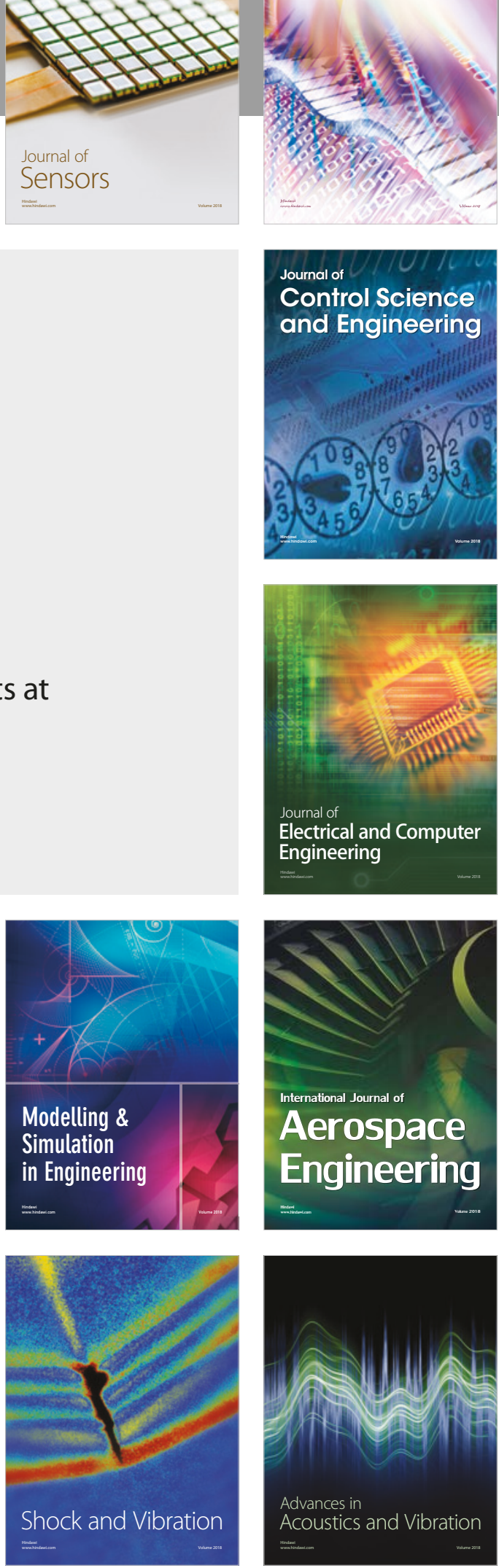